\title{
Soil-Moisture Variability at Big Meadows, Shenandoah National Park, Virginia: Impacts on the Water Balance
}

\author{
Justin Earl Lawrence \\ Charlottesville, Virginia
}

B.S., University of Virginia, 2004

A Thesis Presented to the Graduate Faculty

of the University of Virginia in Candidacy for the Degree of

Master of Science

Department of Environmental Sciences

University of Virginia

May 2007

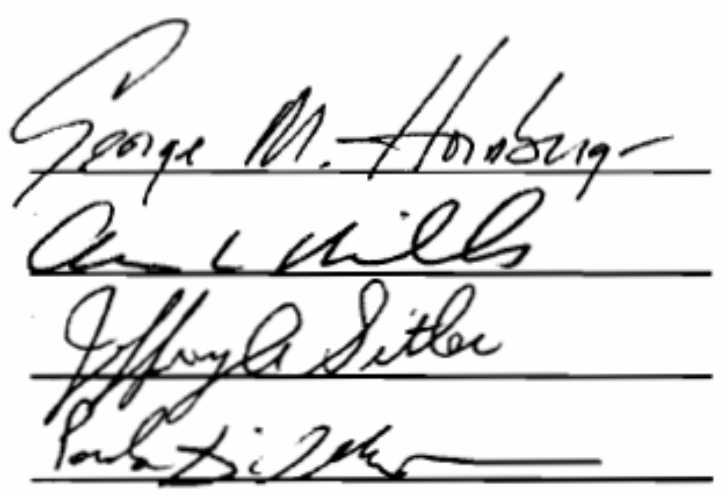




\begin{abstract}
Variability in soil-moisture is controlled by temporal variability in atmospheric conditions and spatial variability in land-surface conditions. In past studies, observations of soil-moisture have revealed a variety of patterns. In some studies, variance increased with decreasing mean moisture content, while in other studies variance decreased with decreasing mean moisture content. These seemingly conflicting observations lead to several open questions: (1) How do spatial patterns of soil-moisture evolve over different time scales? (2) How do topography, soil, and vegetation control the evolution of soilmoisture? (3) How can available data be used with knowledge of hydrologic processes to model the evolution of soil-moisture in small catchments? (4) How does soil-moisture variability impact other parts of the water balance? and (5) How might climate change affect present-day soil-moisture distributions? Soil-moisture patterns were analyzed at Big Meadows, an upland wetland in Shenandoah National Park, Virginia and a different trend from that reported in past studies was found: maximum variance occurred at midmoisture contents instead of low or high moisture contents. An adapted soil-moisture dynamics model, driven by hourly inputs of temperature and precipitation, was used to reproduce observed spatial patterns of soil-moisture. The deep drainage component of the soil-moisture dynamics model was related to ground-water levels and stream discharge, and gave reasonable results. The results of this study provide insight into the controls of soil-moisture variability, may generally apply to sites in temperature climate zones, and can be used to forecast effects of climate change on soil-moisture patterns.
\end{abstract}




\section{Acknowledgements}

I thank the members of my Master’s Thesis Committee, George Hornberger, Aaron Mills, and Paolo D’Odorico from the Department of Environmental Sciences, University of Virginia, and Jeffrey Sitler from the Office of Environmental Health and

Safety, University of Virginia, for their time, expertise and encouragement. I also thank Sam Flewelling and Quintin Brubaker for their help in the field, and Janet Herman for convincing me to return to the University of Virginia for graduate school.

This work was funded by the National Park Service, PMIS\#: 81588 


\title{
Table of Contents
}

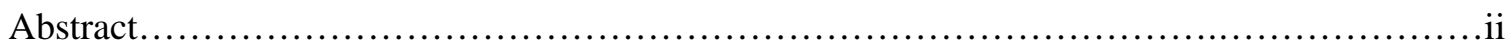

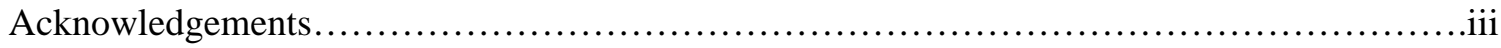

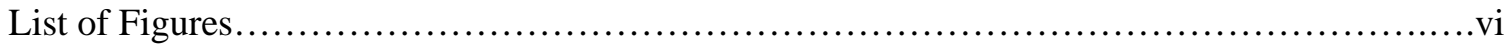

List of Tables.............................................................................
\end{abstract}

Chapter 1: Introduction.......................................................

Chapter 2: Methods........................................................6

2.1 Site specific information..........................................

2.2 Volumetric moisture content.......................................9

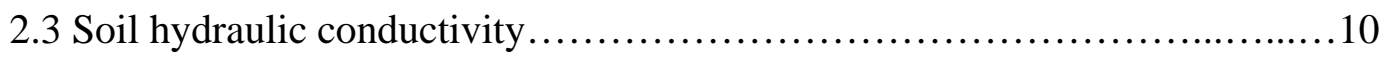

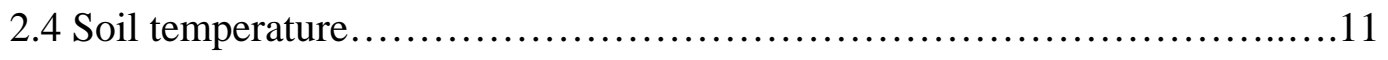

2.5 Slope and aspect.................................................11

2.6 Soil texture analysis.............................................12

2.7 Atmospheric conditions.........................................13

2.8 Soil-moisture model............................................... 14

2.9 Ground-water....................................................

2.10 Ground-water model...............................................17

2.11 Stream Flow........................................................

2.12 Discharge model................................................20

2.13 Climate change.................................................20 
Chapter 3: Results.........................................................22

3.1 Soil-moisture patterns...........................................22

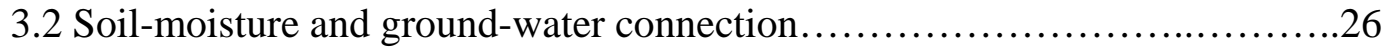

3.3 Soil-moisture model..............................................27

3.3.1 Uniform precipitation assumption...........................27

3.3.2 Slope factor as an index for exposure..........................28

3.3.3 Model results.............................................30

3.4 Ground-water.........................................................

3.5 Stream flow.....................................................33

3.6 Normal climate variability and climate change..........................36

Chapter 4: Discussion..................................................38

References...............................................................42

Appendix A......................................................................44

Appendix B............................................................45 


\section{List of Figures}

Figure 1. Big Meadows, Shenandoah National Park, Virginia..........................6

Figure 2. Locations of wells, soil moisture sites, and streams.......................8

Figure 3. Soil-moisture measured with the two TDR instruments.....................9

Figure 4. Example quadratic equation from the infiltration curve.....................11

Figure 5. Topographic characteristics at the soil-moisture observation sites............12

Figure 6. Precipitation from 1997 to 2005 at Big Meadows, Virginia versus the state-wide precipitation for Virginia from the long-term dataset.............................. 13

Figure 7. Derived annual precipitation at Big Meadows from 1895 to 2005 with trend

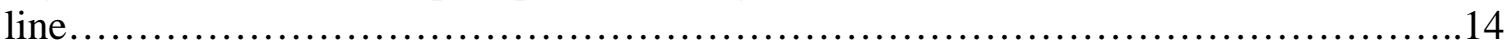

Figure 8. Grid used for finite-element model ...................................18

Figure 9. Measured conductivity after addition of $200 \mathrm{~g} \mathrm{NaCl}$ into stream..............19

Figure 10. Rating curve for salt dilution gauging...................................

Figure 11. Seasonal patterns; Winter, Spring, Summer and Fall......................22

Figure 12. Time-series following the dry down after storm on 27 Jun $2006 \ldots \ldots \ldots \ldots \ldots . .22$

Figure 13. Observed mean moisture content and precipitation over study period........23

Figure 14. Observed variance and precipitation over study period...................23

Figure 15. Exemplar soil-moisture patterns as a function of wetness..................25

Figure 16. Percentages of the total observation area in different soil-moisture ranges for specific mean volumetric moisture contents, derived from field observations...........25

Figure 17. Variability about the mean captured with different spatial aggregations......25

Figure 18. Mean soil-moisture and groundwater levels in meadow...................26

Figure 19. Mean soil-moisture and ground-water levels during dry down...............26

Figure 20. Precipitation from the meteorological station during $2006 \ldots \ldots \ldots \ldots \ldots \ldots \ldots . . .27$ 
Figure 21. Variability among the 4 rain gauges on 5 different days....................28

Figure 22. Slope factor and soil temperature data................................29

Figure 23. Histogram of slope factors from days that soil temperature was measured....29

Figure 24. Bin-centered $S_{\mathrm{f}}$ vs. the mean temperature for each bin......................30

Figure 25. Variance vs. mean soil-moisture content..............................31

Figure 26. Recorded water levels in wells at Big Meadows...........................32

Figure 27. Ground-water levels in the meadow................................. 32

Figure 28. Finite-element model of ground-water heads............................33

Figure 29. One-step-ahead prediction of spring discharge (line) and flows measured by

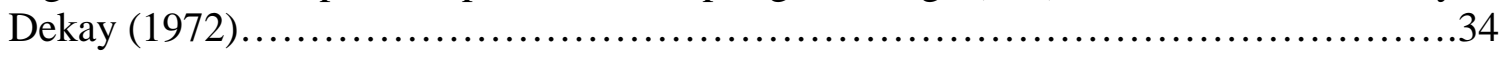

Figure 30. Time-series model prediction with no updating (line) and measured discharge

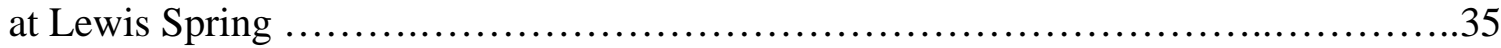

Figure 31. Synthetic discharge time-series for Lewis Spring........................35

Figure 32. Probability plot for annual minimum monthly discharge at Lewis Spring with

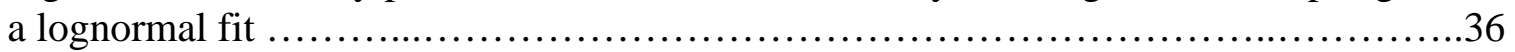

Figure 33. Mean soil-moisture in wet years, dry years, and climate change years ........37 


\section{List of Tables}

Table 1. Model parameters......................................................16

Table 2. Rain gauge measurements.........................................27

Table 3. Stream discharge measurements.......................................33 


\section{Chapter 1: Introduction}

Water is a vital resource for humans, plants, and wildlife. Knowledge of how water flows through natural systems helps people make informed management decisions. If made brashly, these decisions can result in damage to ecosystems. Although natural systems are infinitely complex, a practical understanding of the hydrology of these systems is possible through careful field observations and rigorous quantitative analyses.

Water balances describe the flow of water through the atmosphere, the soil, the land-surface, and the ground. The study of water flow provides insight into the processes that route water through natural storage reservoirs. Knowledge of the causes of spatial and temporal variations must be part of this understanding. Except for upland catchments with high relief, evapotranspiration is the largest outflow of water in the water balance in temperate climate zones. Because soil-moisture is the main water source for vegetation and evapotranspiration is controlled by vegetation, understanding soil-moisture dynamics is the key to any estimates of terms in a water balance in relatively flat areas.

Although soil-moisture is volumetrically only a small part of the global water budget, it is an essential part of the hydrologic cycle. Soil-moisture affects and links hydrologic processes, including evapotranspiration, infiltration, and runoff (D'Odorico et al. 2000). Soil-moisture dynamics are linked with those of atmospheric processes and of vegetation through interlinked feedback loops (Rodriguez-Iturbe 2000). Because soil-

moisture is a control in the energy exchange between the land surface and the atmosphere (Brubaker and Entekhabi 1996), an understanding of how coupled processes give rise to observed spatial and temporal variation is an important scientific goal in hydrology. To 
achieve this goal, the controls on spatial variability in soil-moisture, how it changes in time, and how it is influenced by topography, soils, and vegetation must be sorted out.

Observations of soil-moisture have shown a variety of patterns. Grayson et al. (1997) observed that soil-moisture patterns in a field are characterized by persistent wet and dry periods. D'Odorico and Porporato (2004) suggested that bimodality in temporal distributions of soil-moisture might be evidence of a soil-moisture precipitation feedback, although Teuling et al. (2005) argued that there was insufficient evidence to support this claim. Famiglietti et al. (1999b) observed spatial variability in soil-moisture to increase with decreasing mean moisture content, while Western and Grayson (1998) observed spatial variability in soil-moisture to decrease with decreasing mean moisture content. Clearly, the soil-vegetation-atmosphere feedbacks with soil-moisture are complex and explanations for observed patterns are likely to involve a number of variables.

Statistical distributions of soil-moisture have been analyzed in past studies. Loague (1992) observed that soil-moisture was distributed normally along a linear transect, and non-normally among a set of grid points. Famiglietti et al. (1999a) observed the distribution to evolve from negatively skewed, non-normal under wet conditions, to normal in mid-moisture ranges, to positively skewed, non-normal under dry conditions. Brocca et al. (2007) reviewed 20 past studies on soil-moisture patterns and found that the data deviated from a normal distribution primarily in areas with high relief, and that the deviation was likely due to lateral redistribution of near-surface water.

Knowledge of the relationship between the mean and variance of soil-moisture patterns is important because it allows researchers to optimize the number of sampling points required to represent the mean, to evaluate the error associated with a certain 
number of points, and to estimate the variability and determine wetness conditions from remotely sensed data. Variance in soil-moisture in humid environments is greater under dry conditions, while variance in semi-arid environments is greater under wet conditions (Brocca et al. 2007). Although previous studies have not classified the relationship between mean soil-moisture content and variance in temperate environments, temperate patterns might reasonably reflect a mix of the patterns observed in humid and semi-arid areas because of the effect of the upper and lower bounds on soil-moisture distributions.

Given our understanding of soil-moisture dynamics, some open questions are:

(1) How do spatial patterns of soil-moisture evolve over different time scales?

(2) How do topography, soil, and vegetation control the evolution of soil-moisture?

(3) How can available data be used with knowledge of hydrologic processes to model the evolution of soil-moisture in small catchments?

(4) How does soil-moisture variability impact other parts of the water balance?

(5) How might climate change affect present-day soil-moisture distributions?

General approaches for examining soil-moisture dynamics include analyzing data collected in the field for statistical relationships, and using models that make use of existing knowledge of hydrologic processes to reproduce observed distributions. Mean and variance are among the most basic statistical indicators that can provide useful information from field observations of soil-moisture. Teuling and Troch (2005) used a simple model to describe soil-moisture dynamics, accounting for variations in soil properties by specifying probability density functions and using Monte-Carlo simulation. 
The model was applied at three catchments in distinctly different environments, and it successfully reproduced some of the main features of observed soil-moisture variability.

As part of a project to characterize the hydrology of Big Meadows in Shenandoah National Park, Virginia, the general approaches suggested above were applied to explore the impacts of spatial and temporal variability in soil-moisture on the water balance. At an elevation of about 1070 meters above sea level, Big Meadows is characterized as a temperate upland wetland and mountaintop meadow that topographically is relatively flat for this location at the crest of the Blue Ridge Mountains. The plants are shallow rooting and sensitive to the amount of water stored in the soil. Soil moisture levels, water-table levels, and stream discharges vary spatially and temporally in response to climate, rainfall and snowfall events, and ground-water pumping for water supply.

Big Meadows was a good site to consider the open questions posed above because the topography is gently sloping, the vegetation cover varies seasonally, the soil type was easily determined (a clay loam), and a meteorological station on-site collects continuous data. In cases such as this, where the land surface deviates even moderately from being flat, casual observations indicate vegetation differences between slopes with different aspects. Measurements of soil temperature and soil-moisture generally show differences that confirm these topographic effects. In addition, soil properties are spatially autocorrelated, so spatial patterns of drainage may be expected to affect soil-moisture.

For this study, observed spatial patterns in soil-moisture from Big Meadows are analyzed over seasonal and storm-time scales. Interestingly, the maximum variance was observed at intermediate soil-moisture contents, which is different from the results reported in other studies. A model adapted from Teuling and Troch (2005) was used to 
explore variability in soil-moisture over the past 100 years, to explore the impacts of soil moisture variability on the water balance, and to hypothesize impacts of climate change. 


\section{Chapter 2: Methods}

Measurements were made with time domain reflectometry (TDR) to determine the seasonal and storm time-scale variation of soil-moisture at Big Meadows (figure 1), allowing estimation of variability. Water-table elevation was measured to determine the impacts of soil-moisture variability on groundwater recharge, and soil-moisture levels and water-table elevation were measured over a two year period (2005-2006) to explore variation on a seasonal and storm time-scale. A soil-moisture dynamics model was used to link soil-moisture with other parts of the water balance; it required measurements of soil hydraulic conductivity, soil temperature, and slope and aspect. A 2-D finite-element model was used with the soil-moisture dynamics model to explore connections with ground-water flow in the underlying aquifer. A predictive time-series model was used with the soil-moisture dynamics model to explore connections with stream discharge. Lastly, the soil-moisture dynamics model was used with synthetic precipitation and temperature data for a 100 year period to explore potential impacts of climate change.

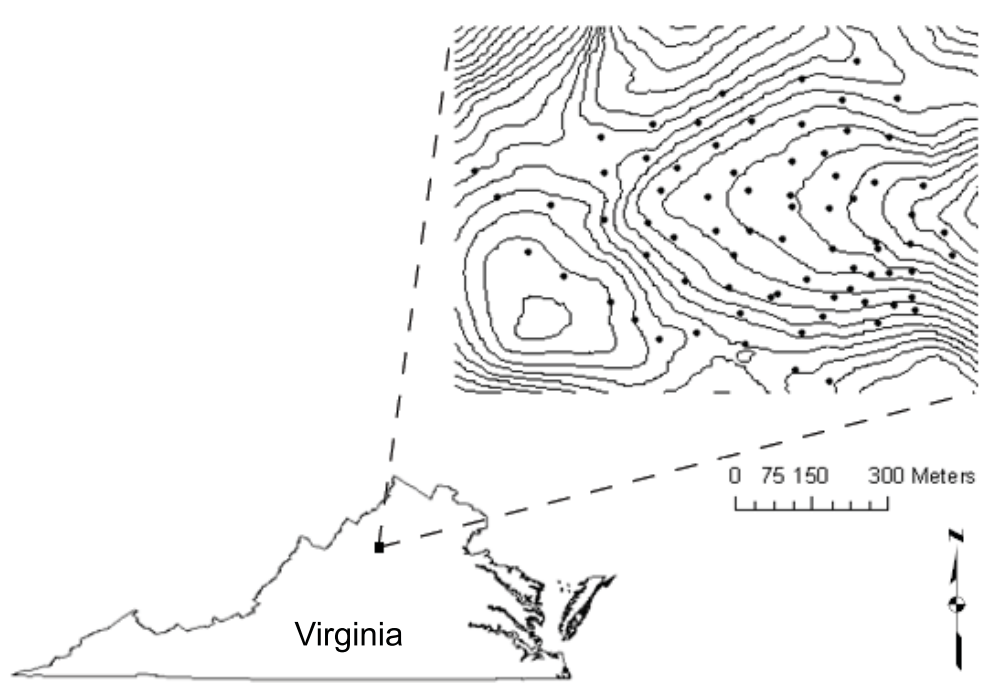

Figure 1. Big Meadows, Shenandoah National Park, Virginia; 2m contour lines, dots represent soil-moisture observation sites. 


\subsection{Site specific information}

At Big Meadows, visitor facilities use water from local sources. For most of the year, the water supply comes entirely from Lewis Spring. During dry periods, groundwater pumping wells are available and can be used to meet additional supply demands.

The local aquifer consists of about 20 meters of highly weathered regolith with primary permeability, underlain by the horizontal beds of the fractured Catoctin metabasalt having only secondary permeability (Lynch 1987). The regolith acts as a large reservoir for infiltration and a pathway to the underlying fractured bedrock system (Martin 2002). Fractures are common in the top $90 \mathrm{~m}$, but not do not extend deeper because of the overlying pressures (Dekay 1972). Ground-water, with an average measured age of 6-7 years, travels quickly through the aquifer (Martin 2002).

Pumping wells BM-9 and BM-14 are located southeast of the visitor center. Only BM-9 is used as a supplemental source when the flow in Lewis Spring is too low. Well BM-3, located northwest of the visitor center, was discontinued in 1992 because USGS scientists determined that pumping from this well might affect water levels in the wetland (Martin 2002). Because it is unknown if pumping from BM-9 affects water levels in the wetland, a crudely calibrated finite-element model was used to illustrate possible effects.

As the main water supply source, discharge at Lewis Spring is of special interest. Dekay (1972) and Lynch (1987) collected discharge records for 1960-70 and 1983-84. Because detailed long-term discharge records are not available, a synthetic record was constructed using the soil-moisture model and it was used to compute low-flow statistics.

Although the soil type was assumed to be homogenous, large boulders and rock outcroppings are present throughout the Big Meadows area. As impermeable surfaces, 
rocks clearly affect soil-moisture patterns in their immediate vicinity. Nonetheless, the rocks covered only a small portion $(<5 \%)$ of the total study area of about $1 \mathrm{~km}^{2}$, and would not be expected to significantly influence the soil-moisture patterns at this scale.

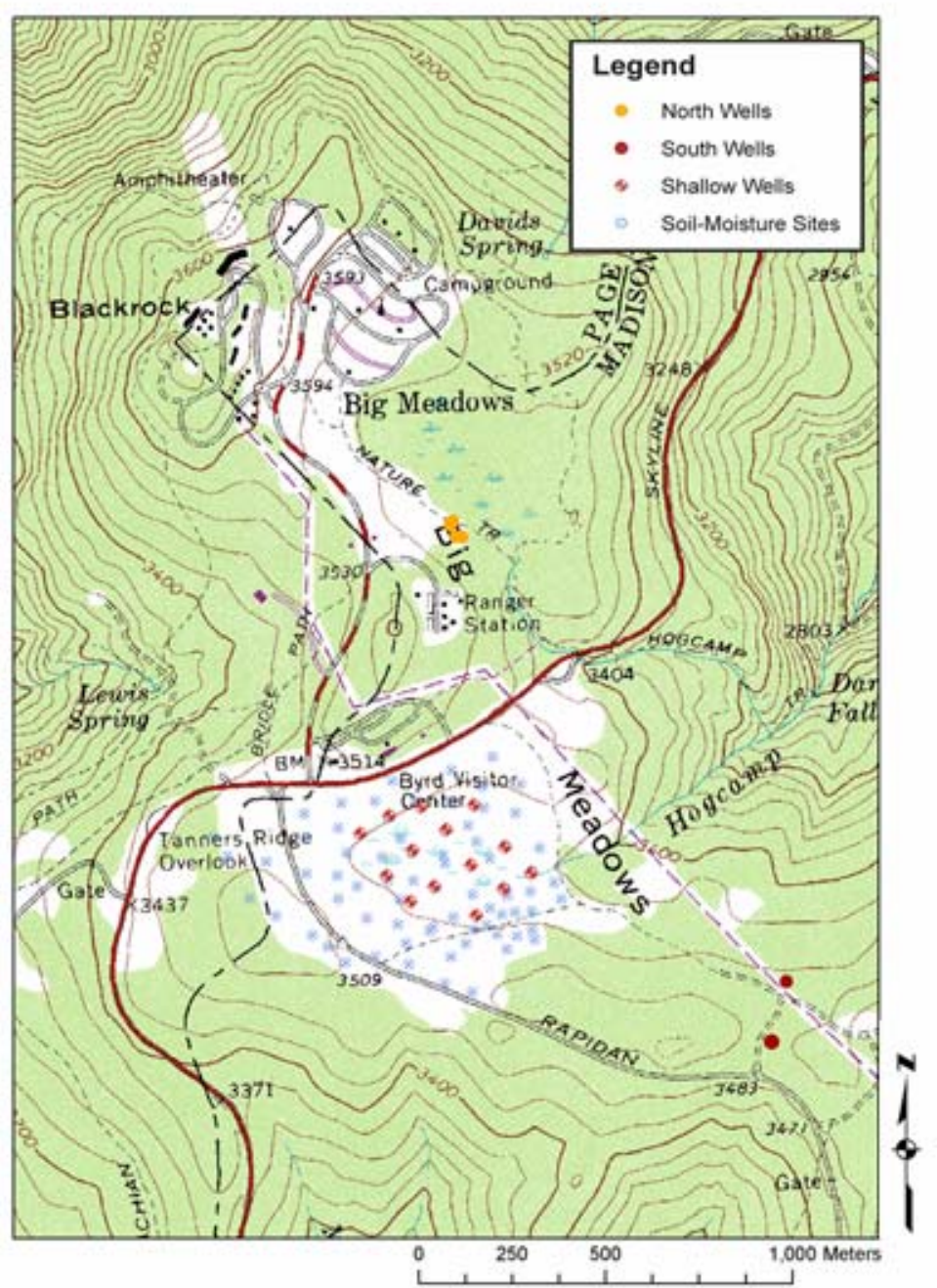

Figure 2. Locations of wells, soil moisture sites, and streams. 


\subsection{Volumetric moisture content}

Soil-moisture was measured at 75 points (figure 2) using a TDR instrument (Spectrum ${ }^{\circledR}$ Field Scout TDR 200) with probes $12 \mathrm{~cm}$ in length, the estimated depth of the root zone. The points were spread throughout the meadow to capture visible changes in the land surface. Measurements were made over the years 2005-2007 to document the spatio-temporal pattern under a variety of atmospheric conditions.

Two TDR instruments were used in the field. To account for differences between the instruments, measurements were made using both instruments to cross calibrate. The readings from the instruments had a linear relationship (figure 3). One instrument read two units higher than the second instrument. To compensate for this difference, two units were added to all measurements made with the second instrument.

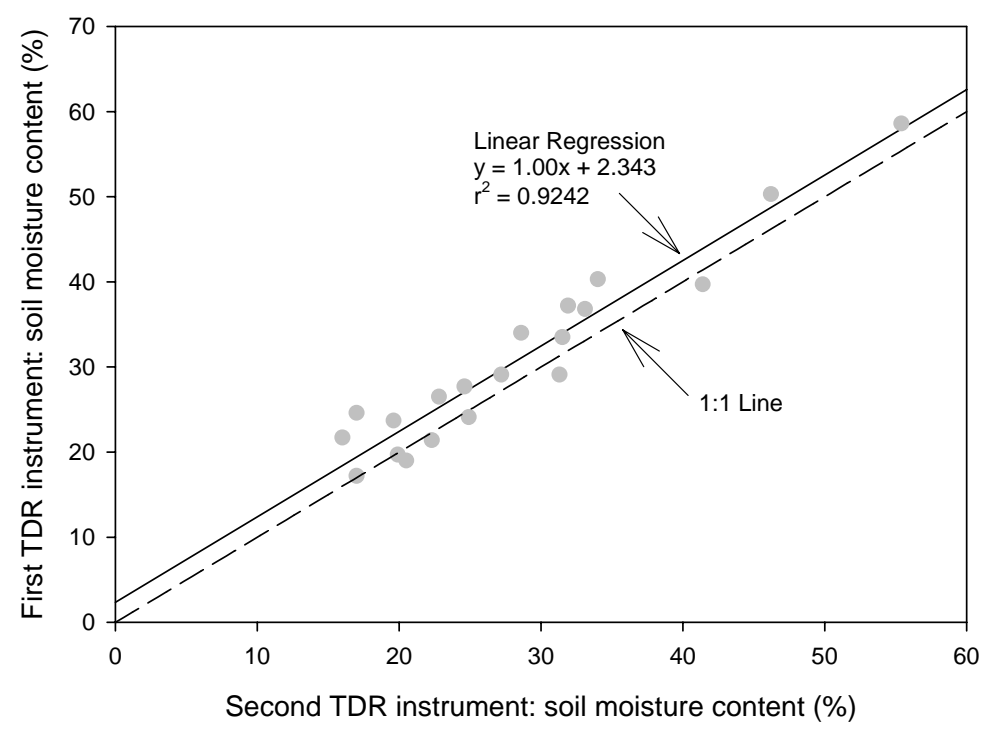

Figure 3. Soil-moisture measured with the two TDR instruments. 


\subsection{Soil hydraulic conductivity}

Soil hydraulic conductivity, $\mathrm{k}$, was measured at the 75 points with a mini-disk infiltrometer under $2 \mathrm{~cm}$ suction; $\mathrm{k}$ was calculated from the cumulative infiltration curve using the method proposed by Zhang (1997), in which a quadratic expression was fit to a cumulative infiltration vs. time plot (figure 4). The hydraulic conductivity equals $\mathrm{C}_{1}$, the coefficient of the $\mathrm{x}^{2}$ term, divided by, $\mathrm{A}$, a value that relates the van Genutchen parameters of a particular soil type to the suction rate and the disk radius.

The value of A, 8.1, was computed from the van Genutchen parameters $-\mathrm{n}$ and $\alpha$ (Carsel and Parrish 1998), the radius of the infiltrometer disk $\left(\mathrm{r}_{0}, 2.2 \mathrm{~cm}\right)$, and the suction at the disk surface, $\left(\mathrm{h}_{0}, 2 \mathrm{~cm}\right)$. The equation is

$$
\begin{array}{ll}
A=\frac{11.65\left(n^{0.1}-1\right) \exp \left[2.92(n-1.9) \alpha h_{0}\right]}{\left(\alpha r_{0}\right)^{0.91}} & \mathrm{n} \geq 1.9 \\
A=\frac{11.65\left(n^{0.1}-1\right) \exp \left[7.5(n-1.9) \alpha h_{0}\right]}{\left(\alpha r_{0}\right)^{0.91}} & \mathrm{n}<1.9
\end{array}
$$

In figure $4, C_{1}$ is equal to 0.028 ; the hydraulic conductivity of the soil is $0.0035 \mathrm{~cm} \mathrm{~s}^{-1}$. The hydraulic conductivity was computed in this way for each of the observation points. 


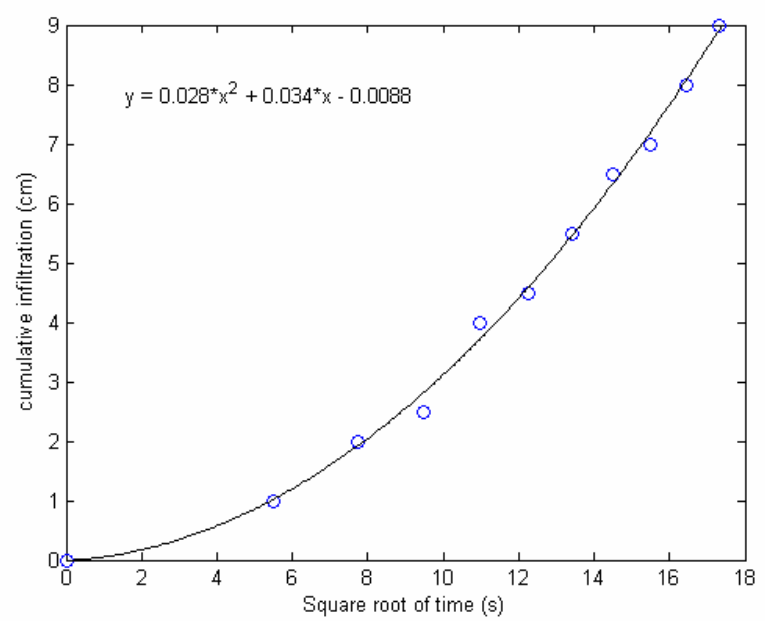

Figure 4. Example quadratic equation from the infiltration curve.

\subsection{Soil temperature}

Soil temperature was measured at each of the observation points with a digital pocket thermometer (Forestry Suppliers, product \#4014). The probe was $20 \mathrm{~cm}$ in length and the reading was accurate to within $\pm 0.1 \mathrm{C}$. Measurements were made by inserting the probe straight down into the soil and waiting 30 seconds before taking a reading.

\subsection{Slope and aspect}

A 7.5' x 7.5' USGS Digital Elevation Model (DEM) was obtained from the Geospatial and Statistical Data Center in Alderman Library at the University of Virginia. A DEM is an array of ground elevations sampled at regularly spaced intervals that represents cartographic information in raster form. The 7.5' x 7.5' DEM corresponds with the USGS 1:24,500 topographic quadrangle and has $10 \mathrm{~m} \times 10 \mathrm{~m}$ spacing with the Universal Transverse Mercator (UTM) projection.

A layer was made in ESRI ${ }^{\circledR}$ ArcInfo 9.1 for the DEM and for the 75 observation points. The aspect and slope functions in the ArcInfo toolbox were used to determine the 
topographic characteristics (Figure 5). The slope raster shows the maximum change in elevation over the distance between a cell and its eight neighbors. Aspect, the compass direction a hill faces, is the steepest down slope direction from each cell to its neighbors.

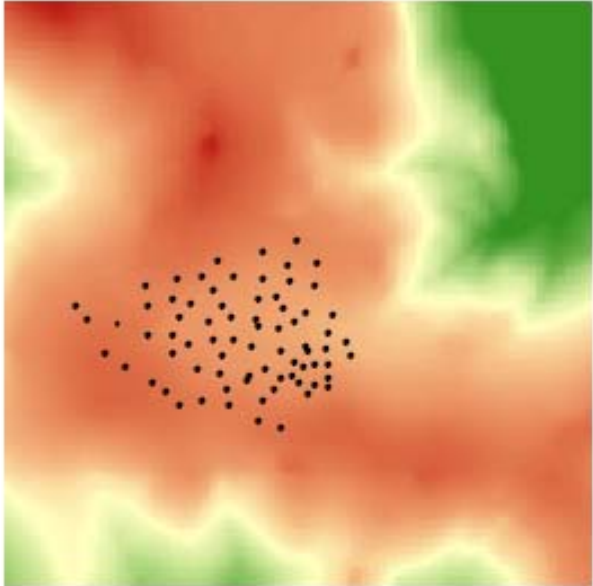

above: input elevation dataset

below: output aspect raster

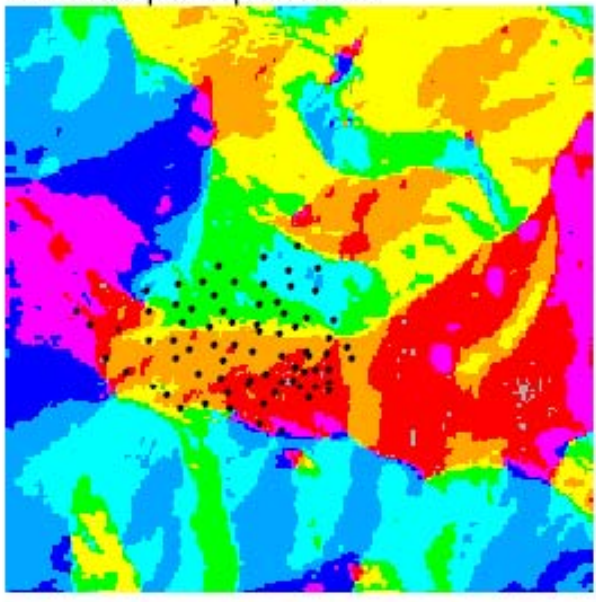

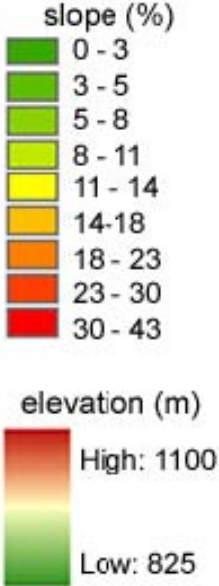

Low: 825

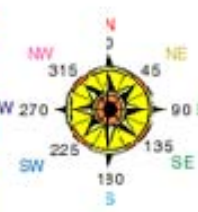
aspect (cardinal) $\square$ Fla: North Northeast Fast Southeast South Southwest West Northwest North

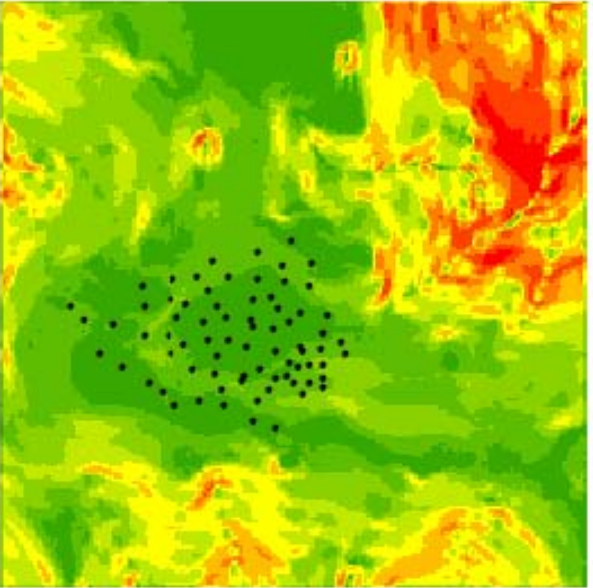

above: ouput slope raster

below: $1: 24,000$ topographic map

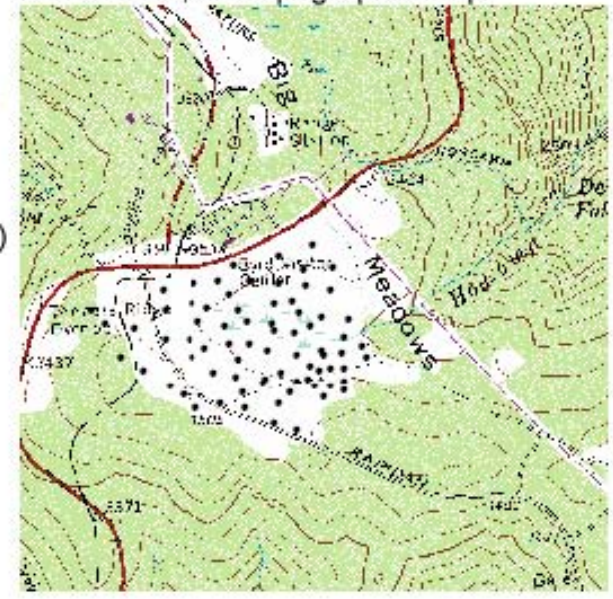

Figure 5. Topographic characteristics at the soil-moisture observation sites (black dots).

\subsection{Soil texture analysis}

The particle size distribution of 9 soil samples from the shallow wells was determined; 3 samples were from $1 \mathrm{ft}$ below the surface, 3 samples were from $1.5 \mathrm{ft}$ below 
the surface, and 3 samples were from $1.8 \mathrm{ft}$ below the surface. Soil texture was classified by mechanical analysis, whereby the ratio of clay, sand, and silt in the samples was determined and matched with the a given soil type in the textural pyramid (Mills 2007).

\subsection{Atmospheric conditions}

Precipitation data for Big Meadows is available beginning in 1997 from the National Park Service (NPS) meteorological station ${ }^{1}$. Four rain gages were installed to test if precipitation is spatially uniform. The rain gauges were operated only a few weeks, just to look at variability relative to the NPS station report. Linear regression (figure 6) was used with historical NOAA precipitation data for Virginia $^{2}$ to extrapolate records from 1997-2005 back to 1895 (figure 7) for climate change analysis. Data from neighboring stations was not used because the records from these stations were not continuous, and much splicing would have been necessary to produce a long-term record.

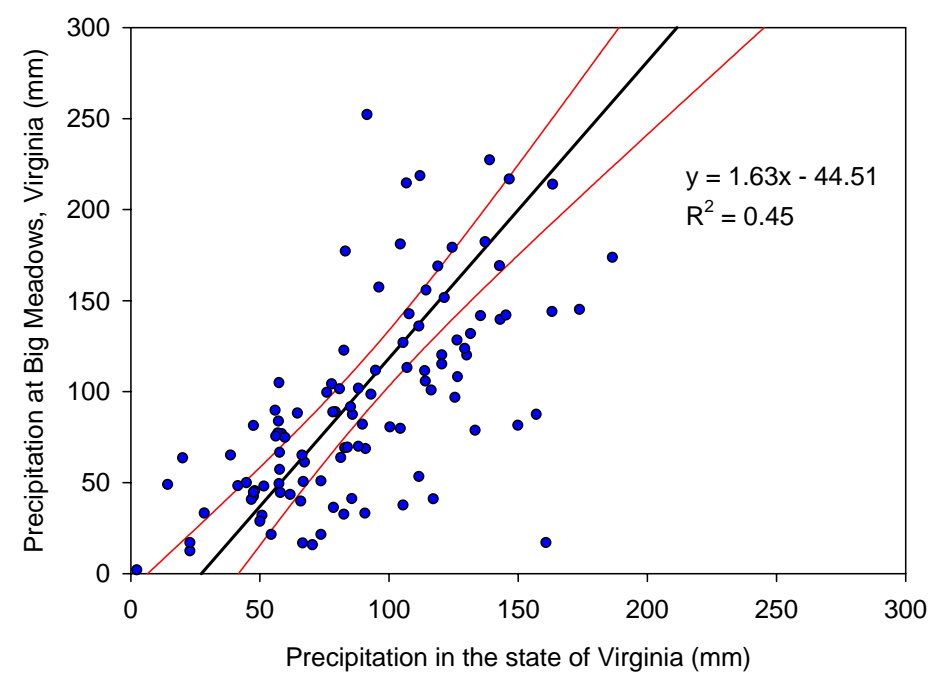

Figure 6. Precipitation from 1997 to 2005 at Big Meadows, Virginia versus the state-wide precipitation for Virginia from the long-term dataset; 95\% confidence intervals.

\footnotetext{
${ }^{1}$ http://ard-aq-request.air-resource.com/

${ }^{2}$ http://www.ncdc.noaa.gov/oa/climate/research/cag3/va.html
} 


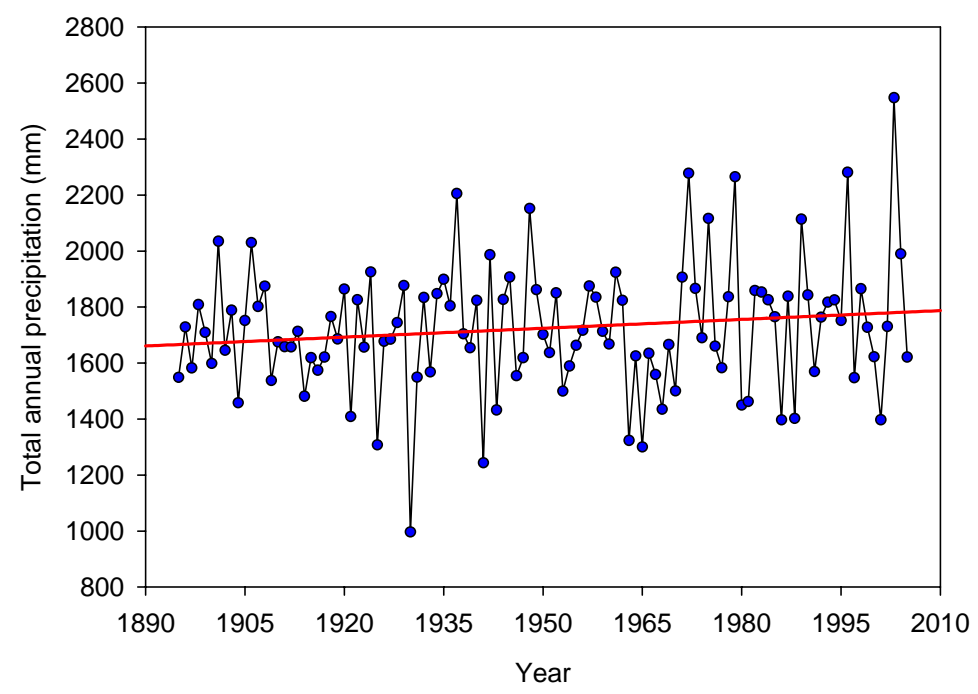

Figure 7. Derived annual precipitation at Big Meadows from 1895 to 2005 with trend line; the $4 \%$ increase in precipitation over the past 100 years is evident ( $p$-value $=0.12$ ).

\subsection{Soil-moisture model}

The Teuling and Troch (2005) model was adapted to use land-surface variables derived from field data and thereby describe observed spatio-temporal patterns. The model inputs included critical moisture content $\left(\theta_{c}\right)$, leaf area index (LAI), precipitation, potential evapotranspiration $\left(E_{p}\right)$, porosity $(\phi)$, and wilting point $\left(\theta_{w}\right)$. It was driven with hourly data for periods of one year. The model can be used to calculate water balances for years outside of the two years of field measurements.

The necessary assumptions were (1) negligible lateral flow in the root zone, (2) negligible bare soil evaporation compared to evapotranspiration from vegetation, and (3) spatially uniform precipitation. For Big Meadows, the shallow slope of the land surface justified the first assumption and dense vegetation cover justified the second assumption. 
The basic Teuling and Troch (2005) model is given by the following equations

Soil-moisture balance $\quad \frac{d \theta_{v}}{d t}=\frac{1}{L}(T-R-q-S)$

$\mathrm{T}=$ throughfall $[\mathrm{L} / \mathrm{T}]$

$\mathrm{R}=$ saturation excess runoff $[\mathrm{L} / \mathrm{T}]$

$\mathrm{q}=$ deep drainage $[\mathrm{L} / \mathrm{T}]$

$\mathrm{S}=$ root water uptake $[\mathrm{L} / \mathrm{T}]$

Deep Drainage $\quad q=k_{s}\left(\frac{\theta}{\phi}\right)^{2 b+3}$

$\mathrm{k}_{\mathrm{s}}=$ saturated hydraulic conductivity

$\mathrm{b}=\mathrm{a}$ pore size distribution parameter

Root water uptake $\quad S=f_{r} \beta[1-\exp (-c \xi)] E_{p}$

$f_{\mathrm{r}}=$ root fraction in the layer of depth $\mathrm{L}$

$\beta=$ a soil-moisture stress function

$c=a$ light use efficiency parameter

Soil-moisture stress $\quad \beta=\max \left[0 ; \min \left(1 ; \frac{\theta-\theta_{w}}{\theta_{c}-\theta_{w}}\right)\right]$

Land-cover $\quad L A I=L A I_{\max }\left[c_{1}-\left(1-c_{1}\right) \sin \left(2 \pi \frac{D O Y-c_{2}}{c_{3}}+\frac{\pi}{2}\right)\right]$

$\mathrm{LAI}_{\max }=$ local maximum of leaf area index

c1,c2,c3 = parameters that specify the seasonal development of LAI

Hourly precipitation and temperature time-series data came from the NPS station. $E_{p}$ was calculated with the Hamon (1961) formula ${ }^{3}$. A process-based approach, such as Priestly-Taylor, would have given a better approximation of $E_{p}$, but sufficient data were

\footnotetext{
${ }^{3}$ The Hamon method is described in Appendix A.
} 
not available to use this type of method. All other parameters (table 1) were fitted from observations or adapted from Teuling and Troch (2005). LAI $\mathrm{Iax}_{\max }$ was taken as the value Teuling and Troch (2005) used for the VCR-LTER site at the eastern shore of Virginia.

To account for topography, $\mathrm{E}_{\mathrm{p}}$ was multiplied by a slope factor, $\mathrm{S}_{\mathrm{f}}$, which is the ratio of radiation received on a sloped surface to the radiation received on a flat surface. $\mathrm{S}_{\mathrm{f}}$ was calculated using a method described by Dingman $(2002)^{4}$ that employs the concept of equivalent slope developed by Lee (1964). The basic idea is that the angle of incidence of radiation on a sloping plane at latitude $\Lambda$ and longitude $\Omega$ is the same as the angle of incidence on an equivalent horizontal plane many degrees longitude removed from the plane.

Table 1. Model parameters

\begin{tabular}{lr}
\hline \multicolumn{1}{c}{ parameter } & \multicolumn{1}{c}{ value } \\
\hline$\theta_{\mathrm{w}}[-]$ & $0.15 \phi^{\mathrm{a}}$ \\
$\theta_{\mathrm{c}}[-]$ & $0.45 \phi^{\mathrm{a}}$ \\
$\mu_{\mathrm{k}}, \sigma_{\xi}[-]$ & $3.6,0.5^{\mathrm{b}}$ \\
$\mathrm{c}$ & $0.55^{\mathrm{b}}$ \\
$\mathrm{f}_{\mathrm{r}}$ & $0.8^{\mathrm{b}}$ \\
$\mathrm{c} 1, \mathrm{c} 2, \mathrm{c} 3[-, \mathrm{d}, \mathrm{d}]$ & $0.5,114,260^{\mathrm{b}}$ \\
$\varepsilon[-]$ & $0.01^{\mathrm{a}}$ \\
\hline $\mathrm{a}$ fitted from observations \\
$\mathrm{b}$ adapted from Tueling and Troch (2005)
\end{tabular}

\subsection{Ground-water}

To examine spatial variability in water-table elevation, 14 shallow monitoring wells, each about $2.5 \mathrm{~m}$ deep, were installed in the meadow; 2 wells south of the meadow (BM-9 and BM-14) and 4 wells north of the meadow were also monitored (figure 2). Three continuous water-level recorders (Solinst $@$ Levelogger LT) were installed; one in a

\footnotetext{
${ }^{4}$ The slope factor, $\mathrm{S}_{\mathrm{f}}$, is described in Appendix B.
} 
well to the north, one in the meadow, and one in a well to the south. Hand-measurements of water levels were made periodically and were used to correct for drift in the data downloaded from the continuous recorders.

\subsection{Ground-water model}

A 2-D finite-element model was constructed to examine how such a model might be useful for examining features of the ground-water system. Constant head boundaries were set at four discharge points: Lewis Spring, Davids Spring, and two branches of Hogcamp Branch. The adapted Teuling and Troch (2005) model was used to estimate a mean recharge of $1360 \mathrm{~mm} /$ year, which was incorporated into the finite-element model. The model was calibrated by adjusting the hydraulic conductivity so that the estimated ground-water levels in wells BM9 and 43 S14 matched the field observations.

The model was constructed with a 48 x 36 grid of 50m x 50m blocks (figure 8). The parameters were rough approximations. The aquifer thickness, b, was taken as $100 \mathrm{~m}$ based on well bore logs. The transmissivity, $\mathrm{T}$, was estimated as $0.0615 \mathrm{~m}^{2} /$ day such that the predicted water-table levels from the model matched the observed water-table levels in the wells in the field. The hydraulic conductivity, $\mathrm{k}=6 \times 15^{-4} \mathrm{~m} /$ day, is within the range for a fractured basalt (Anderson and Woessner 1992). 


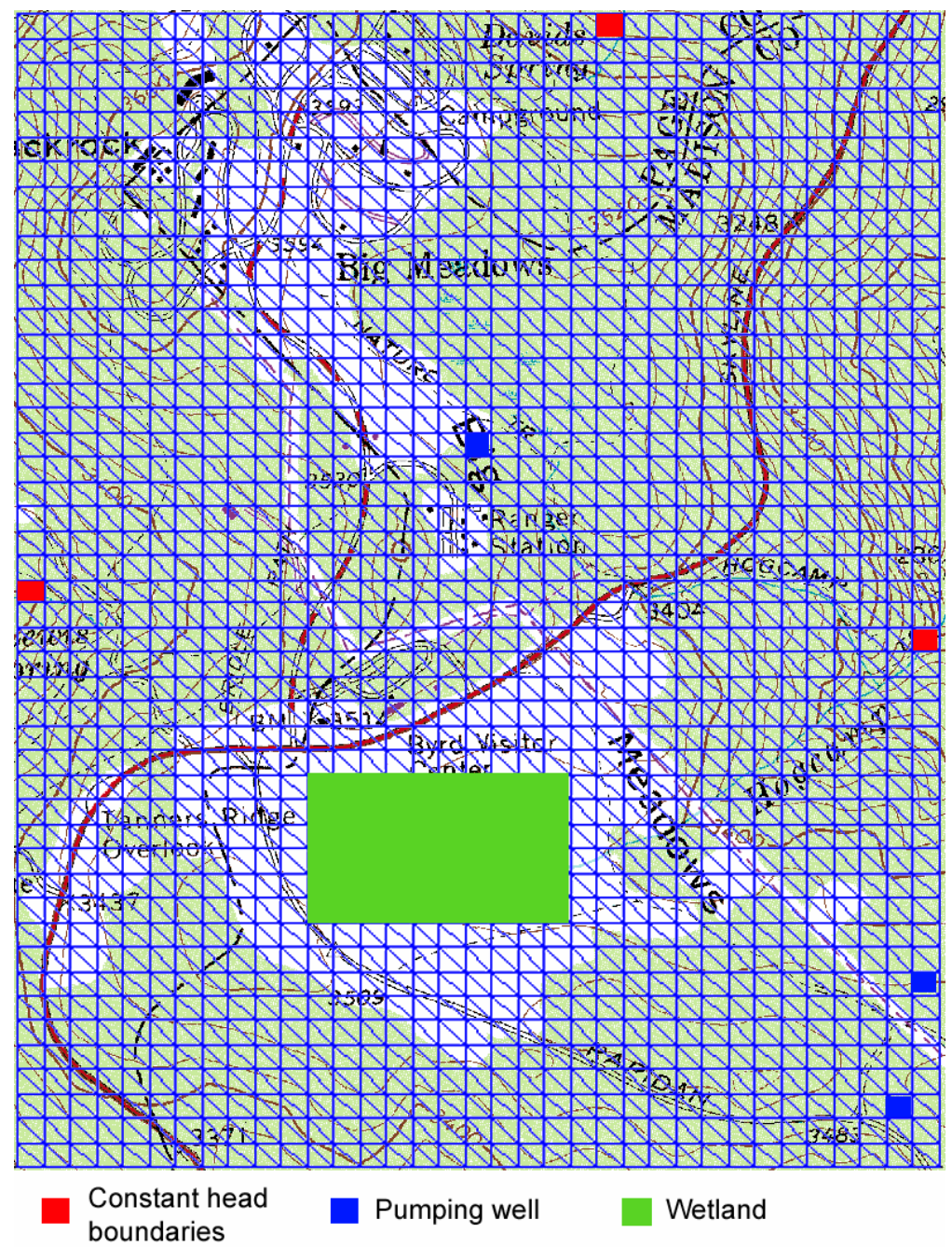

Figure 8. Grid used for 2-D finite-element model (squares are 50m x 50m)

\subsection{Stream flow}

Using a salt-dilution gauging method, the discharge was measured in each of the 4 main streams at Big Meadows: Lewis Spring, Davids Spring, Hog Camp Branch North, and Hog Camp Branch South. The discharge measurements were not meant to generate a continuous record, but merely to determine the sizes of the streams relative to each other.

The method involved pouring 200-300g NaCl into the center of the stream about $100 \mathrm{~m}$ above the measurement point. The $100 \mathrm{~m}$ distance was assumed sufficient for complete mixing to occur; this assumption was tested by computing the theoretical 
mixing length, $L_{\text {mix }}=K_{\text {mix }} \cdot \frac{C \cdot B^{2}}{g^{1 / 2} \cdot Y}$, where $K_{\text {mix }}$ is a mixing coefficient (0.5) for one injection point at the center of the flow, B is average stream width $(2.0 \mathrm{~m}), \mathrm{g}$ is gravitational acceleration $\left(9.8 \mathrm{~m} / \mathrm{s}^{2}\right)$, Y is the average stream depth $(0.25 \mathrm{~m})$, and $\mathrm{C}$ is Chezy's $C=\frac{u_{m} \cdot Y^{1 / 6}}{u_{c} \cdot n}$, where $\mathrm{u}_{\mathrm{m}}=1.00, \mathrm{u}_{\mathrm{c}}=0.552$, and Manning's $\mathrm{n}=0.040$ for a mountain stream (Dingman 2002). The computed mixing length was about 90m; it is thus reasonable to assume that the salt was mixed at $100 \mathrm{~m}$ - the distance of the measurements.

Conductivity was measured every 15 seconds using a YSI conductivity meter (model\# EW-19750-00) until the salt concentration returned to baseline (figure 9). Because the measured conductivities must be related to mass to report in common discharge units (length ${ }^{3} /$ time), a rating curve was constructed using conductivities of a series of known salt concentrations (figure 10). The mass is the integral of the salt flux, $\int(Q \cdot c(t))=M$. For constant $\mathrm{Q}$, the discharge is calculated as $Q=M / \int(c(t))$.

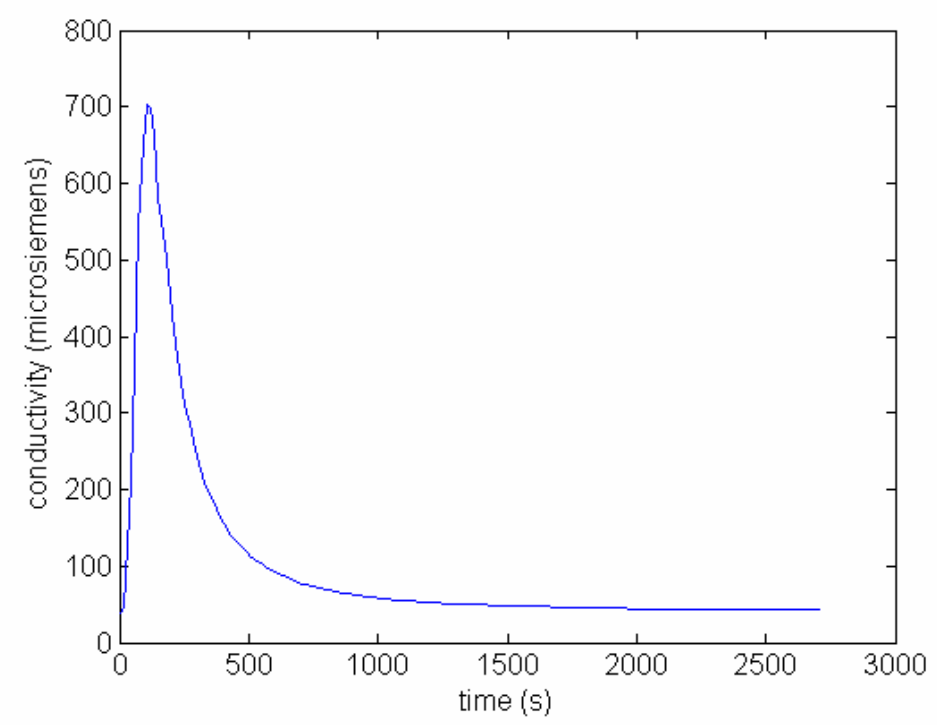

Figure 9. Measured conductivity after addition of $200 \mathrm{~g} \mathrm{NaCl}$ into stream 


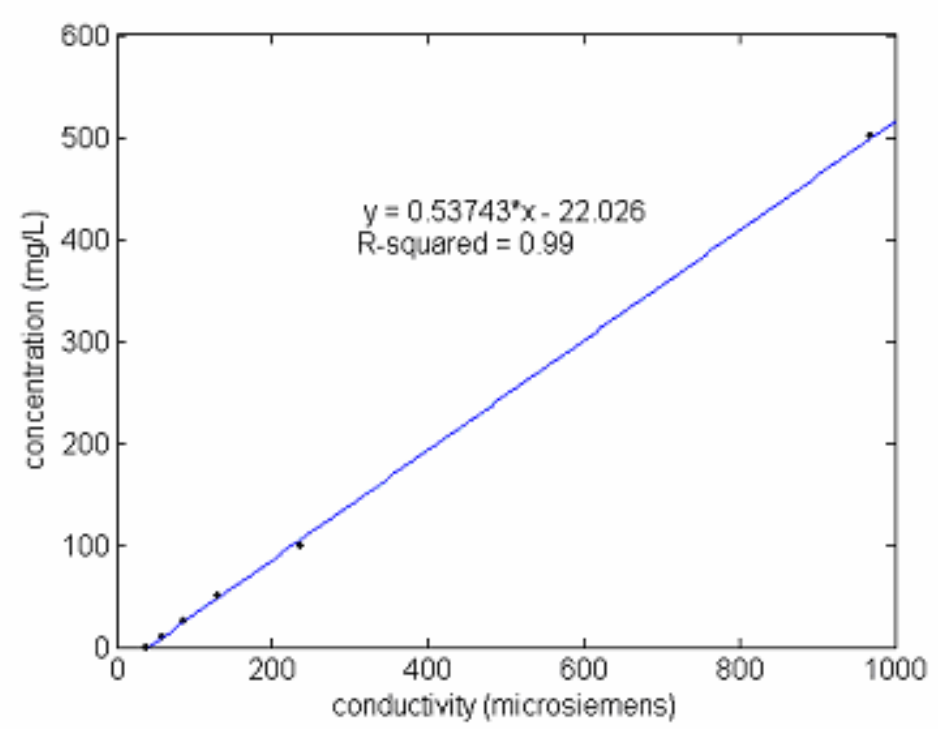

Figure 10. Rating curve for salt dilution gauging.

\subsection{Discharge model}

The deep drainage component from the soil-moisture model was related to the discharge at Lewis Spring using a time-series model, calibrated with a three year period of continuous monthly discharge measurements from Dekay (1972). The fit was done in MATLAB's system identification toolbox using a 110 model and the ARX method. Because hourly precipitation and temperature data were not available from these years, monthly data were smeared evenly over each month into hours. Although this allocation of precipitation will underestimate drainage, it gives a rough approximation of low-flows.

\subsection{Climate change}

Over the last 100 years, precipitation in the United States increased about 4\% (Groisman and Easterling 1994). General-circulation models forecast that increased $\mathrm{CO}_{2}$ in the atmosphere will cause global temperature to rise about 5C in the next 100 years (Kaufmann and Stern 1997). The rise in temperature would produce an increase in 
evapotranspiration rates and the amount of water vapor in the atmosphere, and thereby increase precipitation by 3\% to 15\% (Loaiciga and et.al. 1996).

Data for 1999 were used as a base year to investigate the effects of climate change because 1999 was closest to the long-term trend line (figure 7). As a scenario for climate change, the mean annual temperature was increased by $5 \mathrm{C}$ relative to the base and, to be consistent with the trend over the past 100 years, the mean annual precipitation was increased by 4\%. These increases were chosen to be illustrative, rather than exact.

The data shows that 2001 was a dry year and 2003 was a wet year compared to the long-term average (figure 7). These years were thus chosen to be illustrative of a typical dry year and a typical wet year. To assess how different precipitation and temperature sequences affect soil-moisture levels, the model was used to estimate monthly mean moisture content in a wet year, in a dry year, and in a hypothetical climate change year. Observed spatial patterns in soil-moisture are strongly linked to the mean moisture content. Thus, the spatial pattern can be predicted from a temporal sequence of precipitation and temperature and will have implications for ground-water recharge. 


\section{Chapter 3. Results}

\subsection{Soil-moisture patterns}

The soil-moisture observations had a distinct seasonality (figure 11). On average, the meadow was wettest in winter, when saturated areas were present throughout the area. In spring, the meadow started to dry and saturated areas became more confined. In summer, the mean moisture reached lowest levels. In fall, the meadow wetted up again.
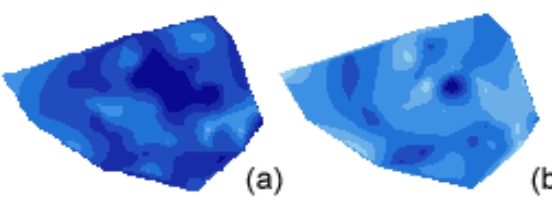

(b)

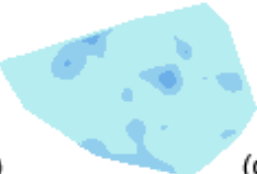

(c)

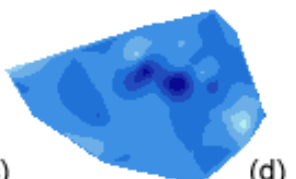

(d)

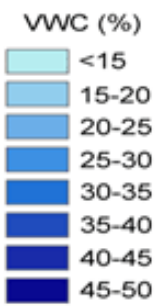

Figure 11. Seasonal patterns; (a) Winter (b) Spring (c) Summer and (d) Fall.

Patterns were also present on a storm time-scale (figure 12). Because most large storms occur in summer, a summer storm was selected to be illustrative. After this storm, the mean moisture content steadily declined 39\% from 28 Jun 2006 to 02 Jul 2006. Variance increased 35\% on the first 2 days following the storm and decreased $36 \%$ on days 3 to 5. In general, highest variance tends to be in the middle of dry down periods.
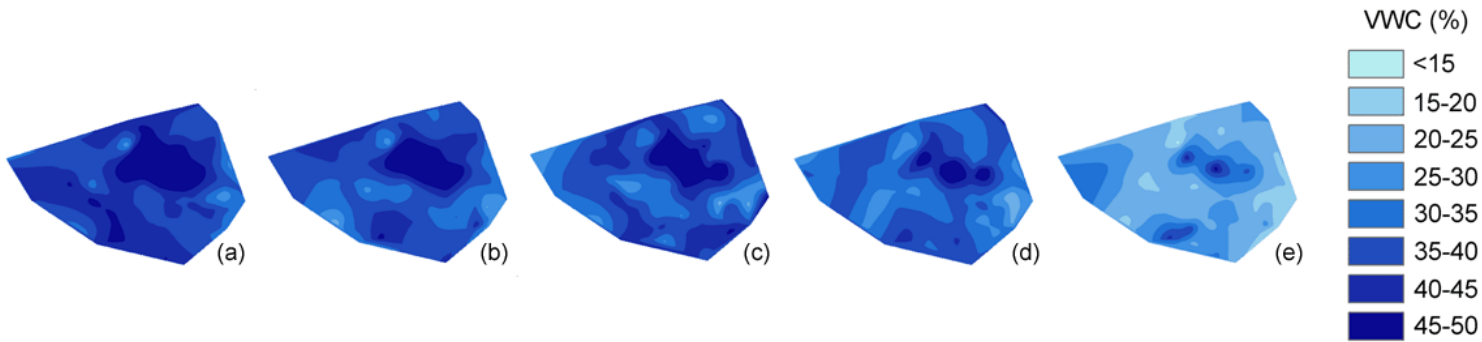

Figure 12. Time-series following the dry down after storm on 27 Jun 2006: (a) 27 Jun, 40.8\%, (b) 28 Jun, 38.0\%, (c) 30 Jun, 37.8\%, (d) 01 Jul, 34.7\%, and (e) 02 Jul, 24.8\%. 
The mean moisture content increased sharply immediately following rainfall events and declined steadily in the days following events. The peak in the mean occurred about 1 day after a rainfall event (figure 13) and the peak in variance occurred after about 3-4 days (figure 14). Although mean and variance peaked at different times, they followed the same general pattern of an increase after events followed by a decrease.

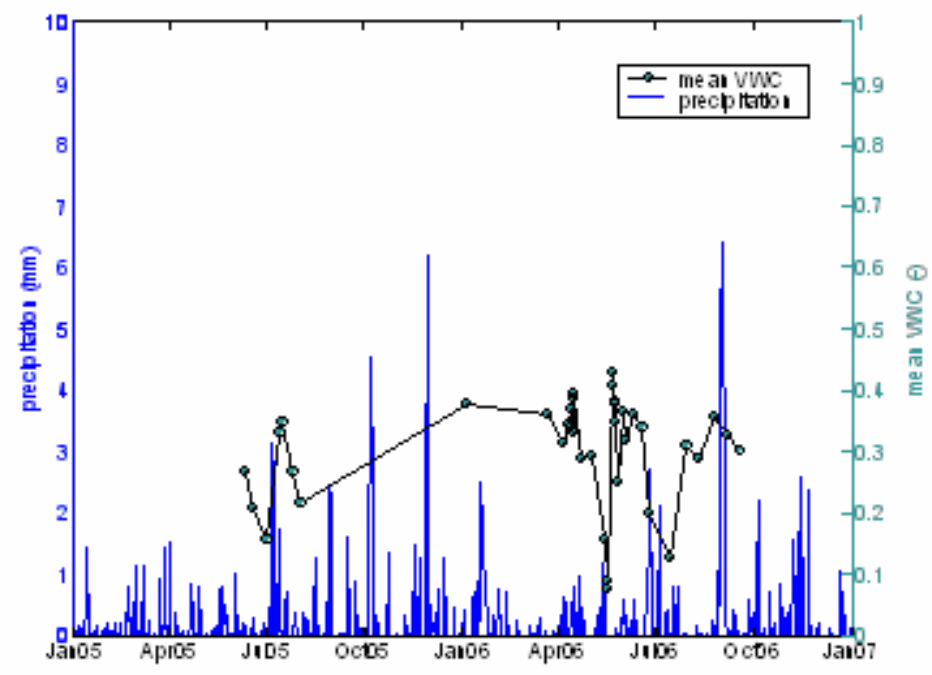

Figure 13. Observed mean moisture content and precipitation over study period.

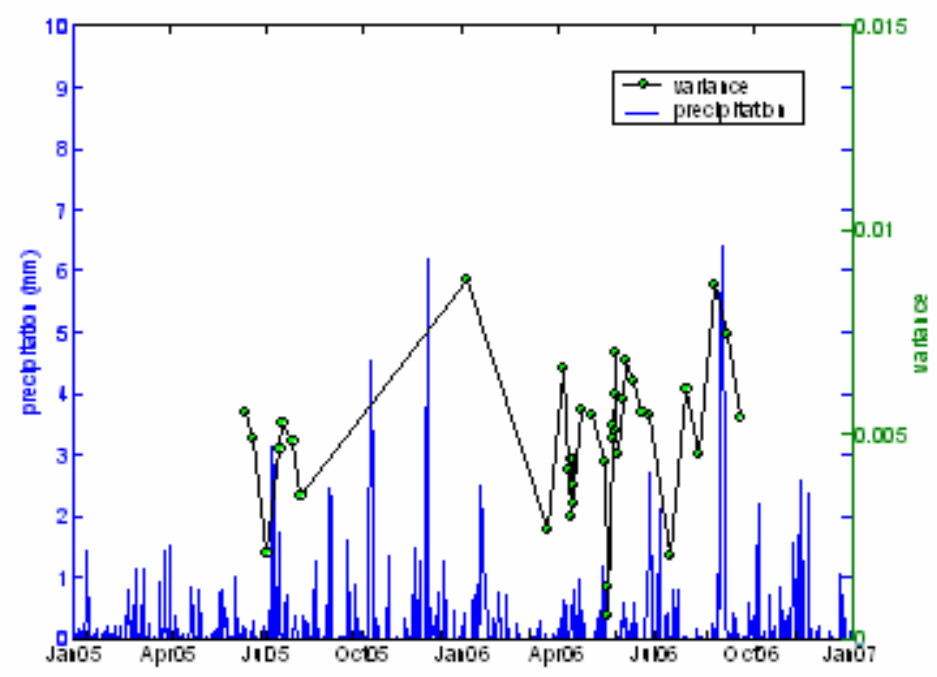

Figure 14. Observed variance and precipitation over study period. 
Distinct trends in the spatial moisture pattern were observed under different wetness conditions (figure 15). Even in the driest times, two wet areas were present near the middle of the meadow. As the meadow soils got wetter, the extent of these two areas increased. Once the wetness reached about 35\%, the two wet areas merged into one large area. The soil with high moisture content was well confined to this large area until the average reached about $40 \%$, at which point more wet areas began appearing in the south.

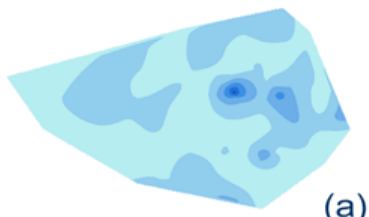

(a)

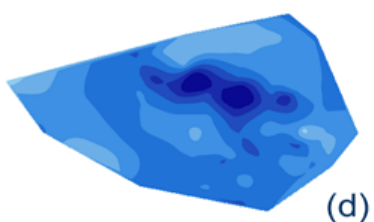

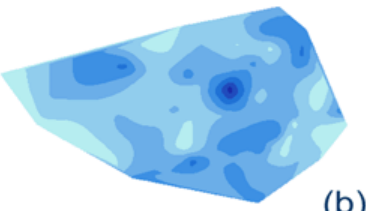

(b)

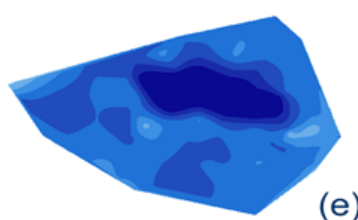

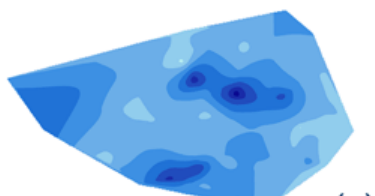

(c)

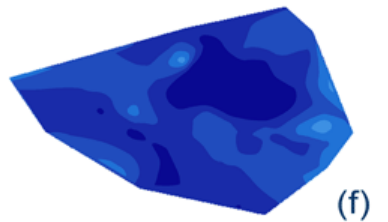

VWC (\%)

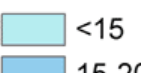

20-25

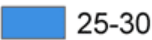

$30-35$

$35-40$

$40-45$

$45-50$

Figure 15. Exemplar soil-moisture patterns as a function of wetness for (a) $15 \%$, (b) $20 \%$, (c) $25 \%$, (d) 35\%, (e) 40\%, and (f) 45\% moisture content; nearest-neighbor interpolation.

The percent of the observation points contained in different moisture ranges was plotted against the mean moisture contents to quantify the portion of the total area in different ranges under different wetness conditions (figure 16). The variability reflects scales from about $50 \mathrm{~m} \times 50 \mathrm{~m}$ to $100 \mathrm{~m} \times 100 \mathrm{~m}$ (figure 17 ). The decline in the $0 \%-20 \%$ moisture range as the meadow got wetter was a sigmoid curve because the distribution was bounded on low end by the field capacity. As the meadow got wetter, the soil filled the 20\%-30\% and 40\%-50\% ranges. These mid-moisture content curves were bell shaped because they were not bounded by soil properties. As the wetness approached the porosity, an increasing portion filled the $40 \%-50 \%$ and $50 \%-60 \%$ ranges. The 
distribution in these high ranges had a long lower tail, bounded on the upper end by the porosity. Soil properties clearly exert a control on the soil-moisture distribution.

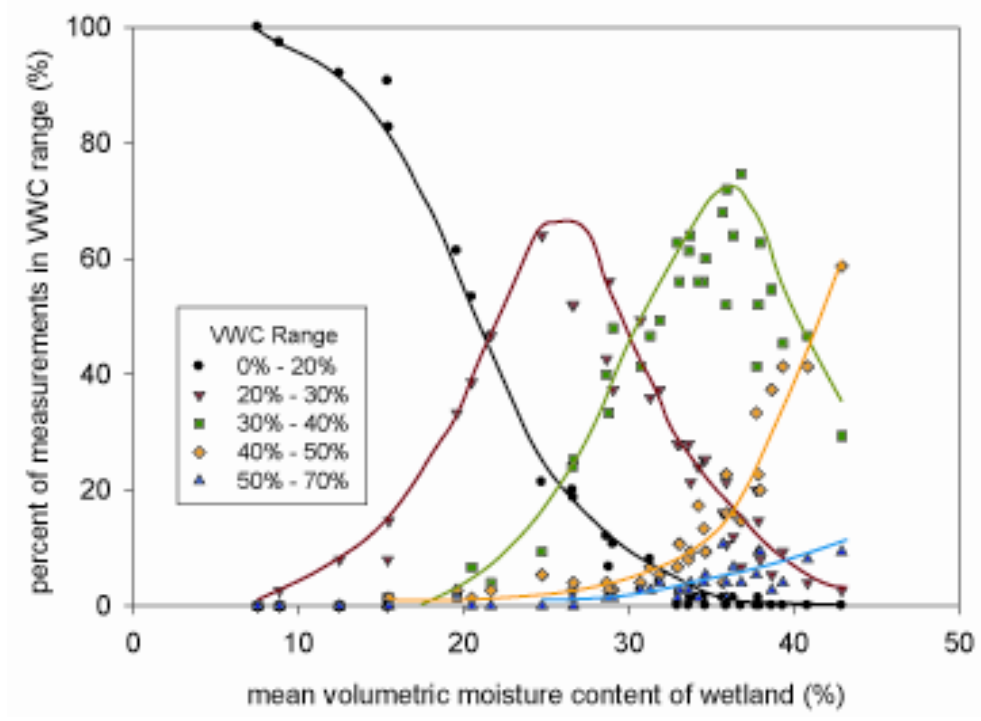

Figure 16. Percentages of the total observation area in different soil-moisture ranges for specific mean volumetric moisture contents, derived from field observations.

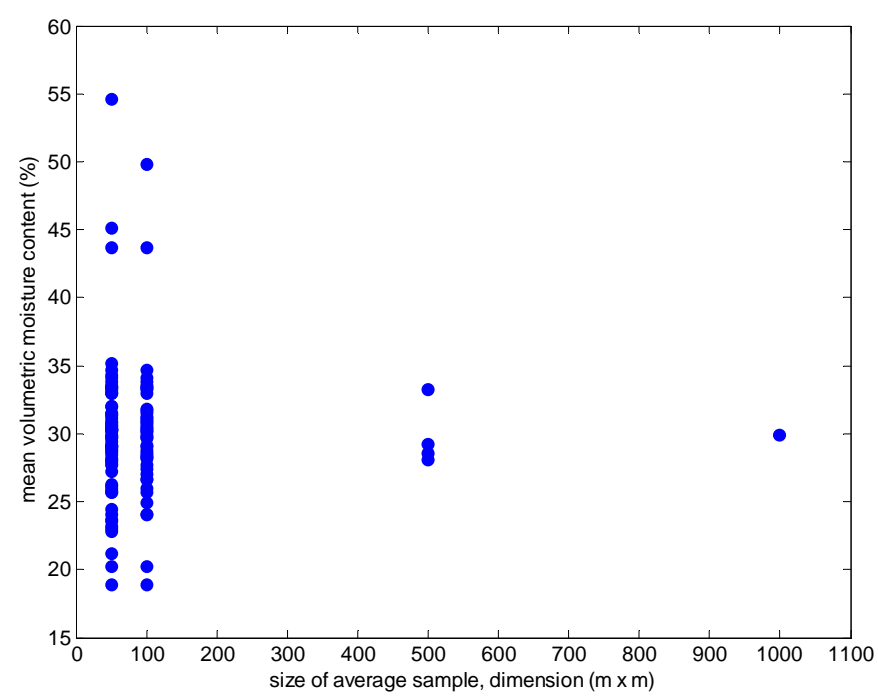

Figure 17. Variability about the mean captured with different spatial aggregations. 


\subsection{Soil-moisture and ground-water connection}

Observations of soil-moisture compare reasonably well with measured groundwater levels (figure 18). The peaks in ground-water levels tend to lag the peaks in soilmoisture by about one day. For the storm on 28 Jun 2006, some of the mean moisture change could quite reasonably have gone into recharge between 6/27 and 6/28 because the ground-water table rose as the moisture content dropped (figure 19).

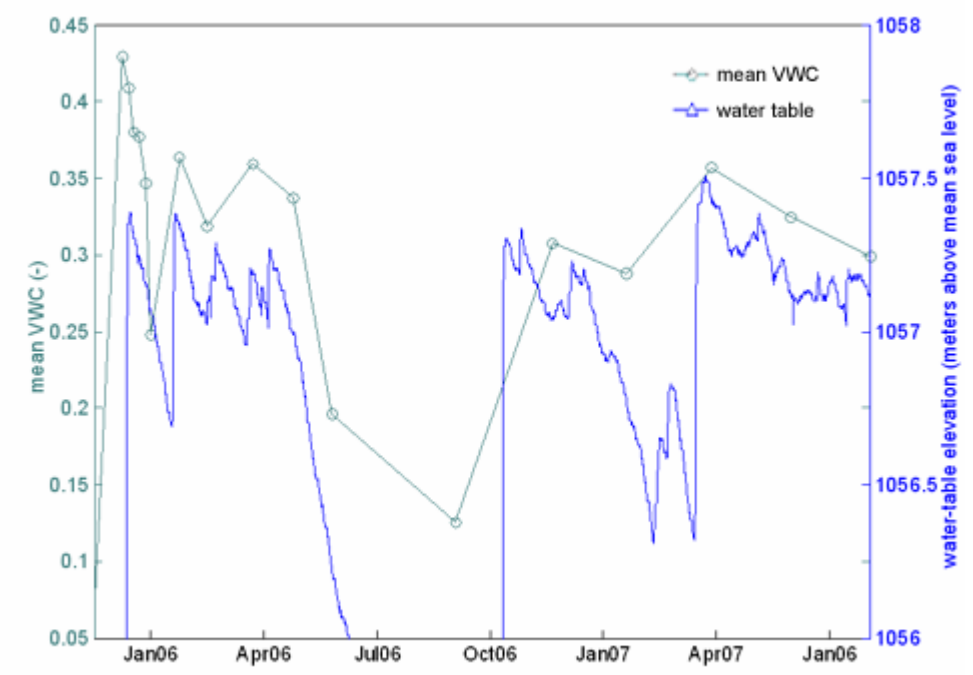

Figure 18. Mean soil-moisture and groundwater levels in meadow

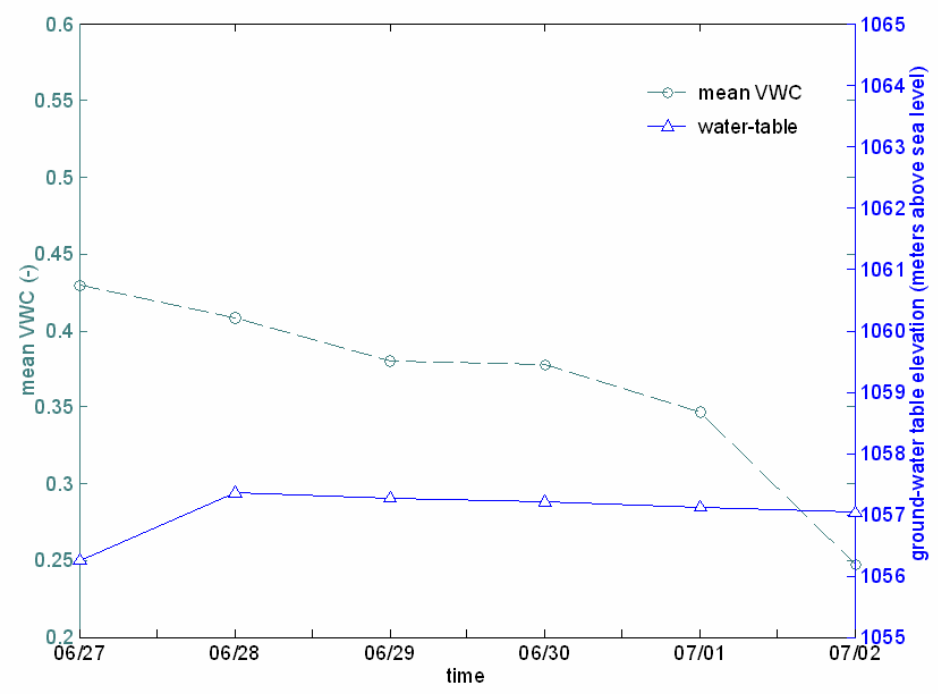

Figure 19. Mean soil-moisture and ground-water levels during dry down. 


\subsection{Soil-moisture model}

\subsubsection{Uniform precipitation assumption}

Measurements from the rain gauges (table 2) validate the assumption of spatially uniform precipitation. The measured water levels conform well to the meteorological station records (figure 20). Variability among the gauges was negligible (figure 21).

Table 2. Rain gauge measurements (mm)

\begin{tabular}{rrrrrrrr}
\hline Gauge & 15-May-06 & 1-Jun-06 & 6-Jun-06 & 19-Jun-06 & 27-Jun-06 & 7-Jul-06 & 12-Jul-06 \\
\hline 1 & 47 & 9.0 & 17.5 & 14 & 110 & 53 & 6.5 \\
2 & 45 & 9.0 & 16.5 & 13 & 120 & 53 & 5.5 \\
3 & 45 & 9.0 & 16.5 & 14 & 125 & 52 & 6.5 \\
4 & 46 & 7.5 & 16.5 & 14 & 122 & 55 & 6.0 \\
\hline
\end{tabular}

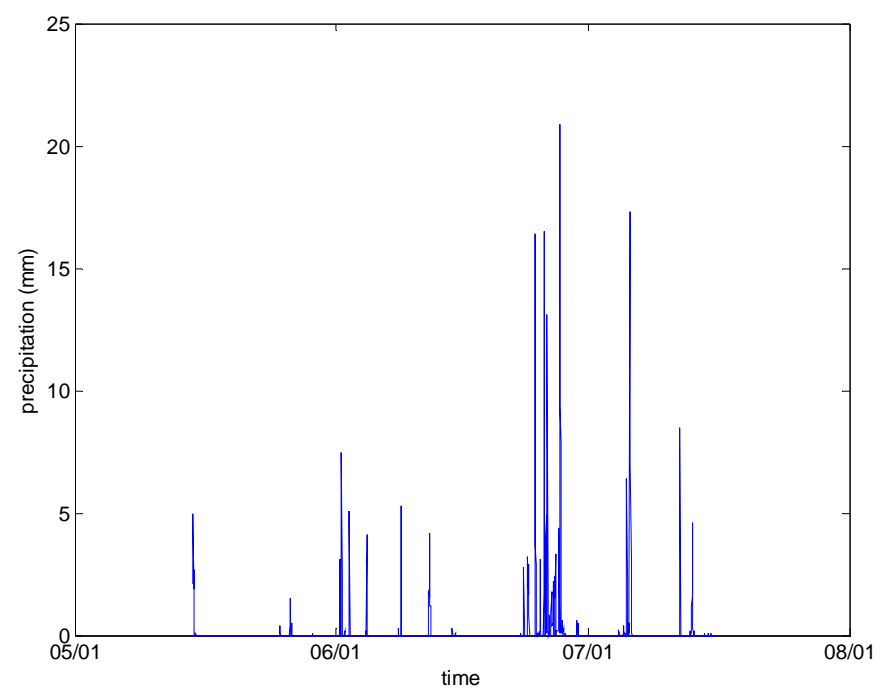

Figure 20. Precipitation at the meteorological station from 01 May 2006 to 01 Aug 2006. 


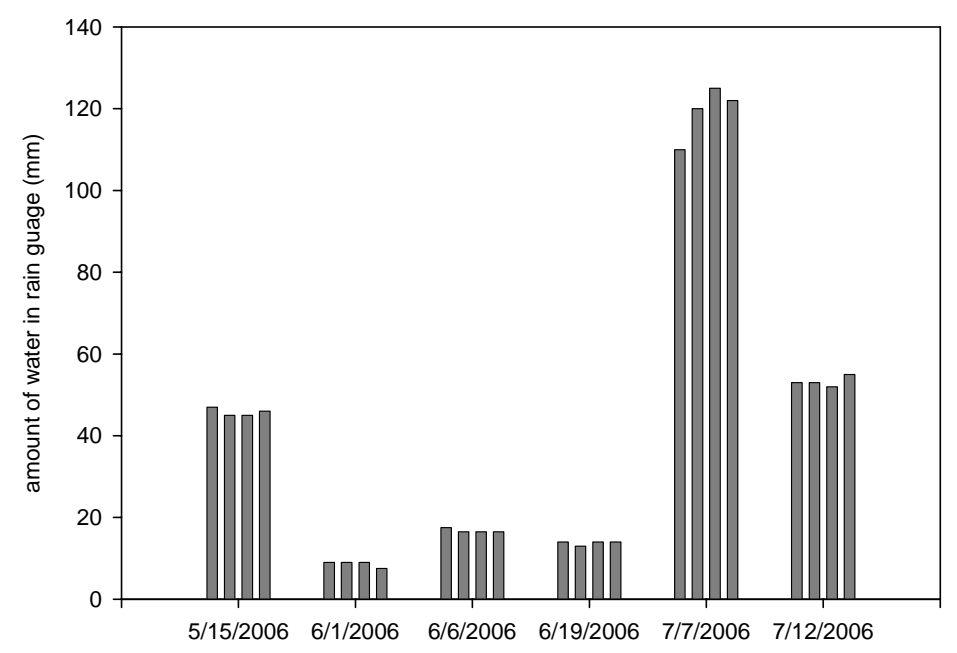

Figure 21. Variability among the 4 rain gauges on 5 different days.

\subsubsection{Slope factor, $S_{f}$, as an index for exposure}

The slopes of the 75 observation points ranged from $0.59 \%$ to $5.6 \%$ grade. The average grade was $2.96 \%$ (SD 1.31). $30.7 \%$ of the slopes faced N, $21.3 \%$ faced NE, 16\% faced E, $14.7 \%$ faced SE, $13.3 \%$ faced S, and 4.0\% faced NW. The placement of the observation points gave a wide range of slopes with a variety grades and aspects.

To test whether it was reasonable to assume that $S_{\mathrm{f}}$ can be used to adjust $E_{\mathrm{p}}$ in the model, soil temperature was measured at each observation point on 20 different days. The plot of $S_{f}$ for these days against the observed temperature had a lot of scatter (figure 22). Because there was much variability in temperature and little in $S_{f}$, values of $S_{f}$ were taken in bins. The $\mathrm{S}_{\mathrm{f}}$ data was aggregated into 8 bins using a histogram to choose the bin sizes (figure 23); the selected bin sizes were 0.994-0.997, 0.997-0.998, 0.998-0.999, 0.999-0.9995, 0.9995-1.000, 1.000-1.0005, 1.0005-1.001, and 1.001-1.004. A plot of the mean temperature was made against the bins and a correlation coefficient was used to test for a relationship between the calculated $S_{\mathrm{f}}$ and the observed soil temperatures. The bin- 
centered $S_{\mathrm{f}}$ versus the mean temperature for each bin showed a strong correlation (figure 24). Thus, in the mean, $S_{f}$ correlates well with temperature and the assumption is valid.

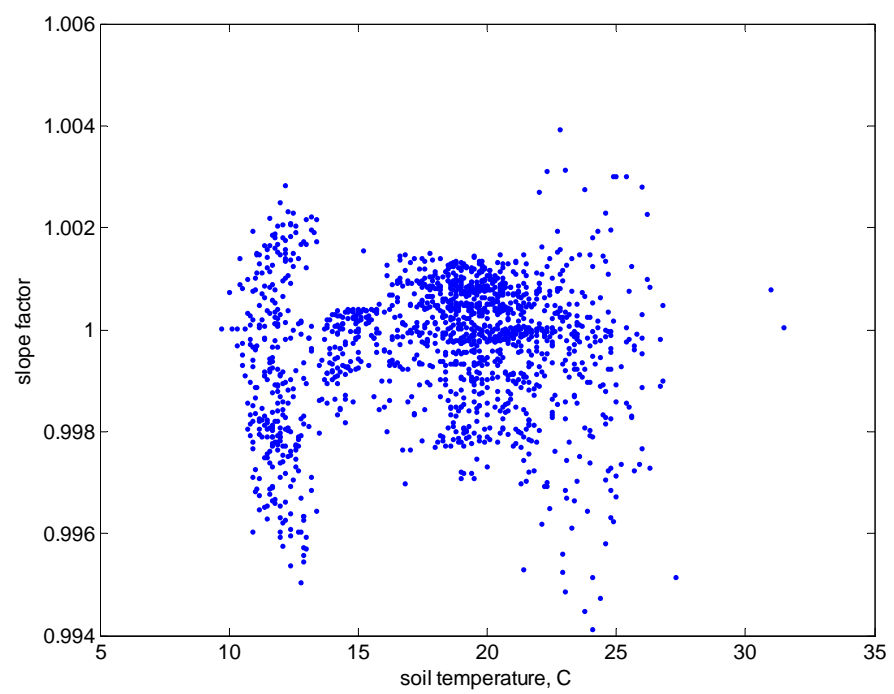

Figure 22. Slope factor and soil temperature data

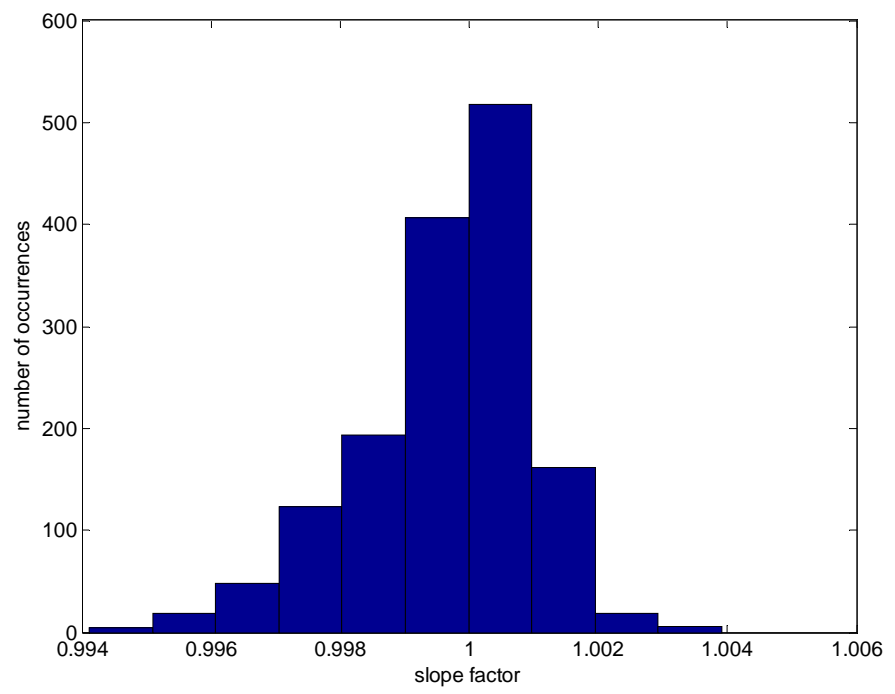

Figure 23. Histogram of slope factors from days that soil temperature was measured 


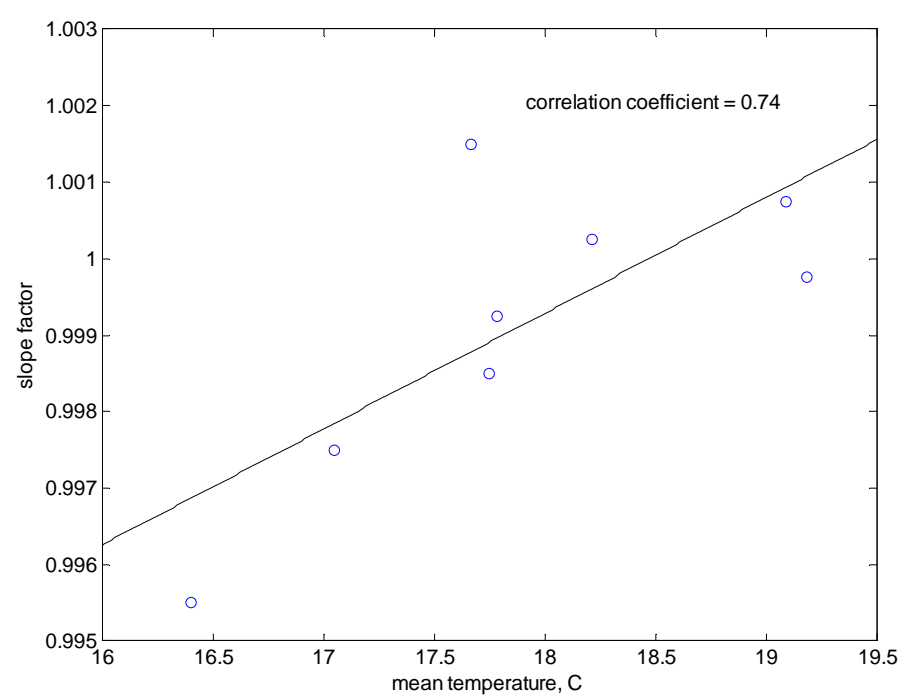

Figure 24. Bin-centered $S_{\mathrm{f}}$ vs. the mean temperature for each bin

\subsubsection{Model results}

The adapted Teuling and Troch (2005) model captured the relationship between total variance and the mean moisture content (figure 25). The variance was controlled by the wilting point under low moisture conditions and by the porosity under high moisture conditions. Because the model tended to show a bias and an over-prediction of variance, some adjustments of the model results were necessary to bring them into conformance with the observed soil-moisture patterns. The porosity was adjusted by increasing the observed soil-moisture from the day after a large storm by $25 \%$, and multiplying by a scaling factor of 5 . The wilting point was set to equal the porosity multiplied by 0.15 . With these simple adjustments, the model fit the observations reasonably well. 

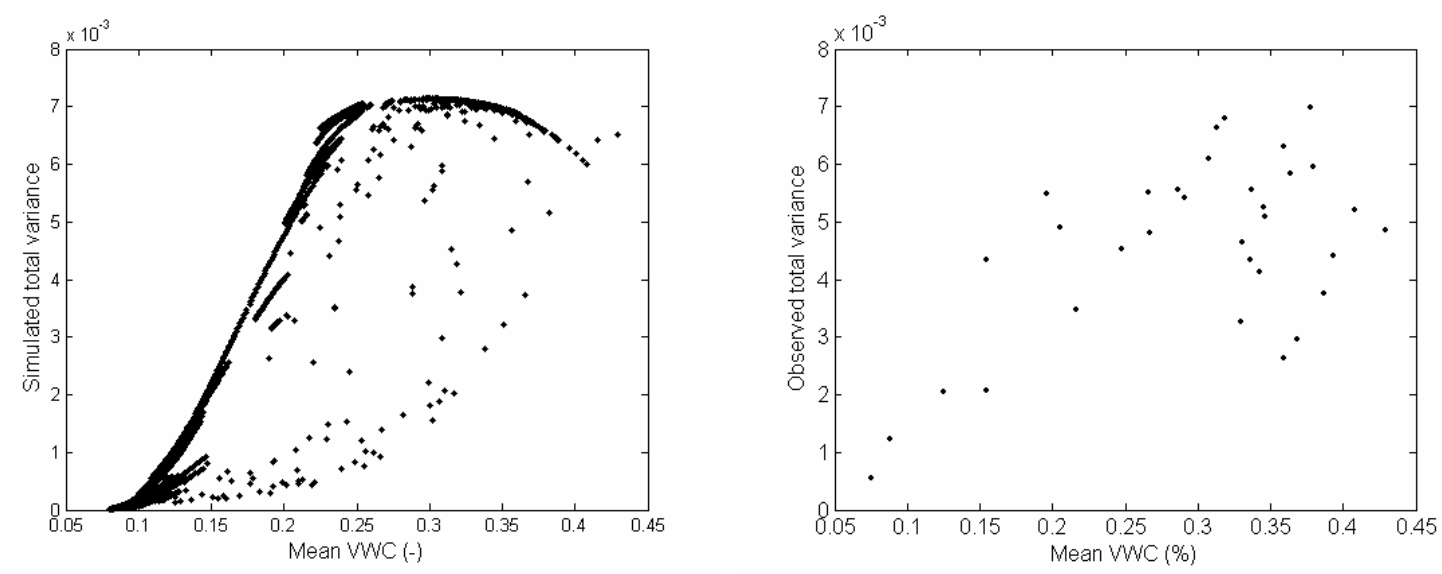

Figure 25. Variance vs. mean soil-moisture content

\subsection{Ground-water}

Continuous hydrographs show distinct temporal responses to precipitation events (figure 26). The shallow water-table in the meadow responds substantially and quickly to precipitation events, whereas well BM9, about $750 \mathrm{~m}$ from the wetland, responds much more slowly. The 14 shallow monitoring wells showed temporal responses that were all similar to each other (figure 27), and different from the response in the deep wells.

The finite-element model gives a rough approximation of the effect that pumping from well BM-9 might have on water levels in the meadow. This assumes the aquifers at these two wells are connected; essentially, it's a worst case scenario for the effect of pumping. Several plausible pumping rates were tested: 20 gpm, 40 gpm, and 60gpm.

With no pumping, the model gives a ground-water level in the meadow of 1057.0 $\mathrm{m}$, in agreement with the observed hydrograph (figure 28). At 20 gpm the water level drops to $1056.7 \mathrm{~m}$, at $40 \mathrm{gpm}$ to 1056.4 , and at $60 \mathrm{gpm}$ to $1056.2 \mathrm{~m}$. The simulated changes are all within the observed range of natural variability. Only when the pumping exceeds 70 gpm does the water level drop below the observed range in the hydrographs. 


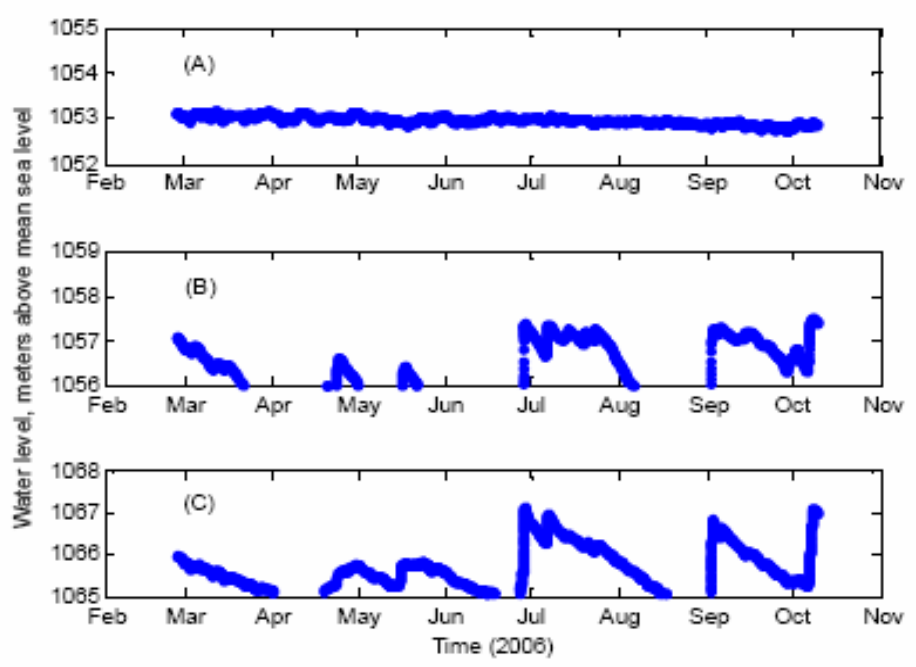

Figure 26. Recorded water levels in wells at Big Meadows: (A) well BM9, $107 \mathrm{~m}$ depth; (B) piezometer in meadow, 2.5m depth, (C) well 43 S14, 16.7 m depth

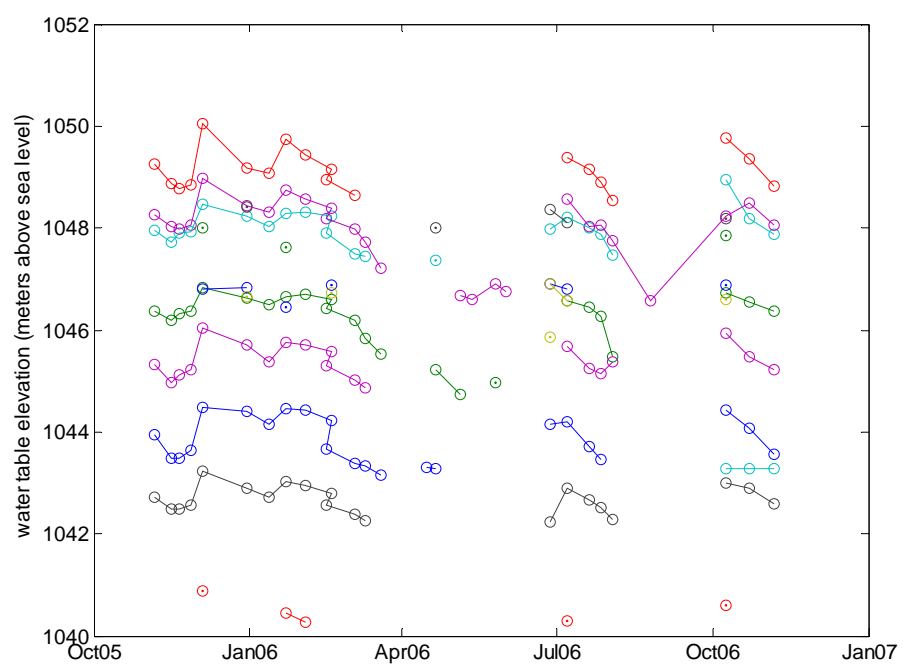

Figure 27. Ground-water levels in the meadow; each line is a different monitoring well. 


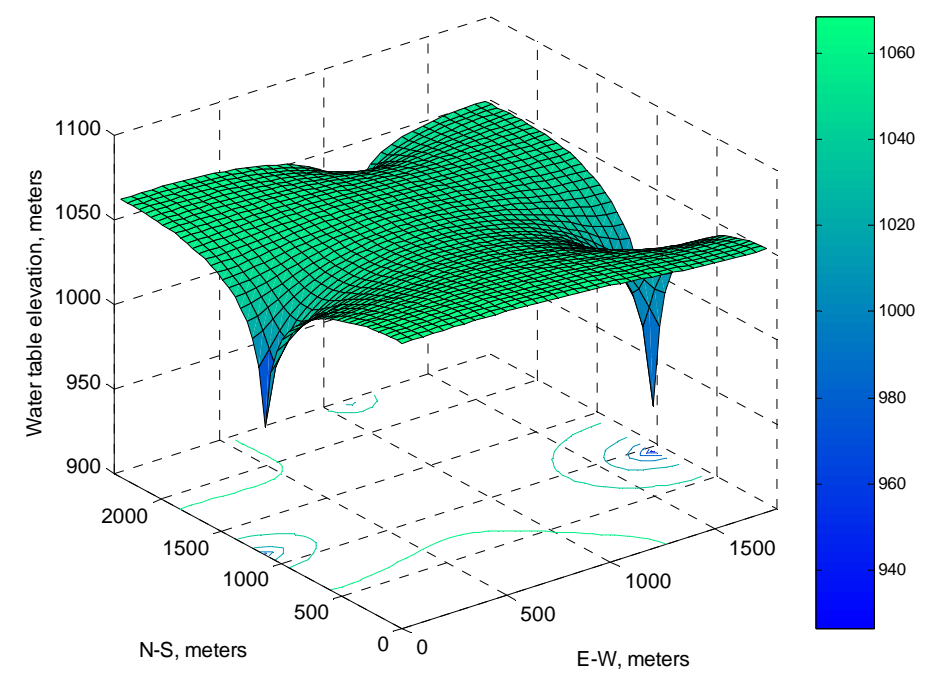

Figure 28. Finite-element model of ground-water heads.

\subsection{Stream flow}

The discharges (table 3) of the streams were measured using salt dilution gauging. Lewis Spring had the highest flow. The south branch of Hog Camp Branch had the second highest, the north branch had the third highest, and Davids Spring had the lowest.

Table 3. Stream discharge measurements

\begin{tabular}{clr}
\hline \multicolumn{1}{c}{ Date } & \multicolumn{1}{c}{ Location } & Discharge (gal/min) \\
\hline $7 / 12 / 2006$ & Hog Camp Branch South & 188.6 \\
$7 / 18 / 2006$ & Hog Camp Branch South & 131.6 \\
$7 / 20 / 2006$ & Hog Camp Branch North & 112.5 \\
$7 / 27 / 2006$ & Davids Spring & 36.5 \\
$8 / 3 / 2006$ & Lewis Spring & 202.9 \\
\hline
\end{tabular}

The discharge model for Lewis Spring is $\hat{Q}\left(t_{j}\right)=0.6974 Q\left(t_{j-1}\right)+0.5547 q\left(t_{j}\right)$, where $\hat{Q}\left(t_{j}\right)$ is the estimate of discharge in month j in millions of gallons, $\hat{Q}\left(t_{j-1}\right)$ is the estimated discharge for the previous month, and q is the deep drainage component from the soil-moisture model. When the model is run with a one-step ahead prediction with 
the Dekay (1972) data, the low flow results are good (figure 29). Even if the model is run as a straight prediction, the low flow results are reasonable (figure 30). High flows are simulated poorly because smearing monthly data into hours misses high intensity events. A synthetic discharge record for Lewis Spring was produced using the 100 years of synthetic historical data derived from the long-term data for Virginia run through the regression model (figure 6). The low flows are simulated reasonably well (figure 31). For each of the 100 years of record, the minimum monthly discharge was selected to create an annual series. A lognormal distribution fit these data (figure 32).

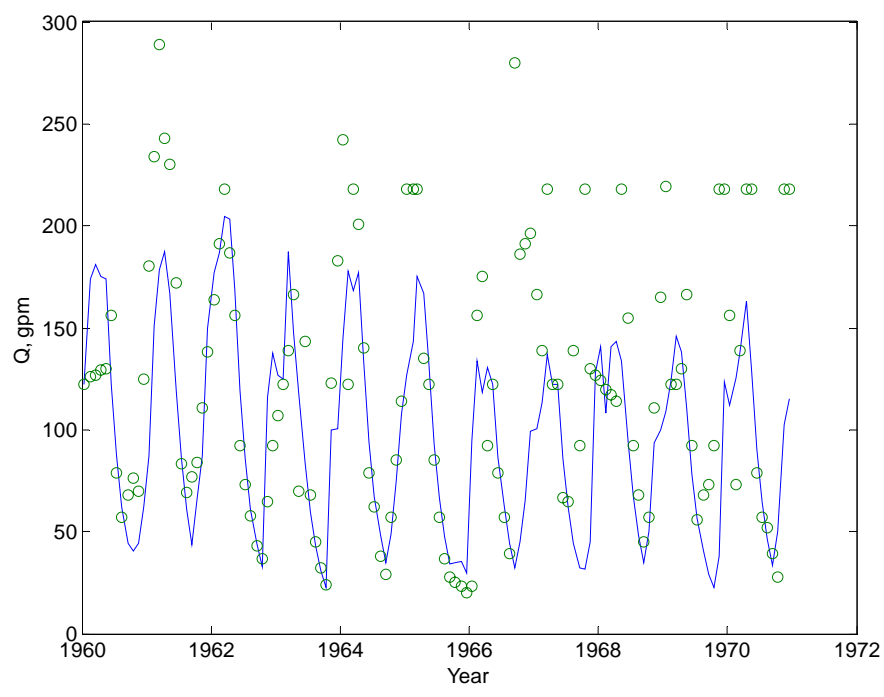

Figure 29. One-step-ahead prediction of spring discharge (line) and flows measured by Dekay (1972). 


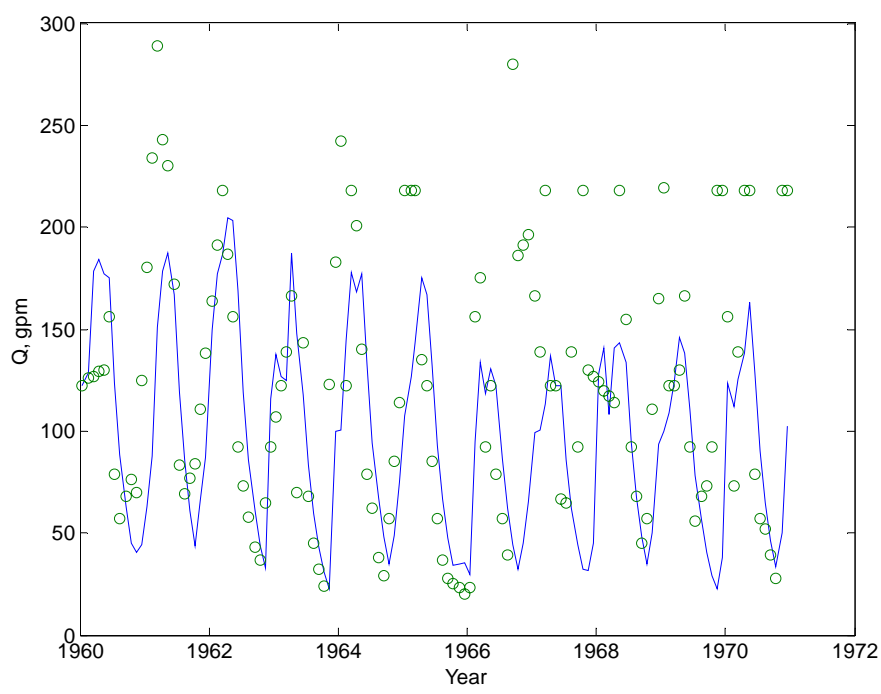

Figure 30. Time-series model prediction with no updating (line) and measured discharge at Lewis Spring (circles).

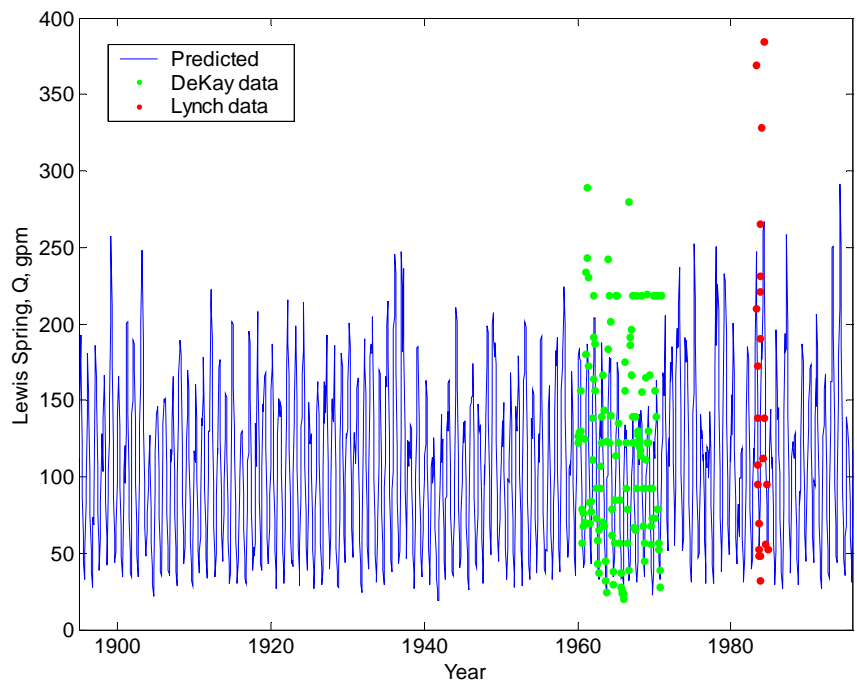

Figure 31. Synthetic discharge time-series for Lewis Spring. 


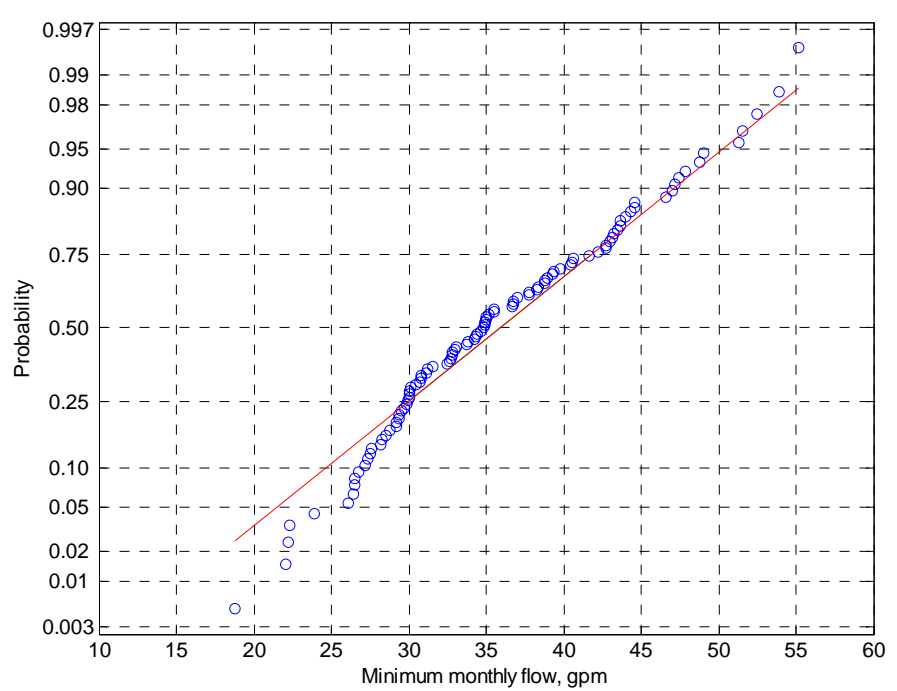

Figure 32. Probability plot for annual minimum monthly discharge at Lewis Spring with a lognormal fit (red line).

\subsection{Normal climate variability and climate change}

The mean soil-moisture is sensitive to climate variability (figure 33). The meadow is most wet from November to April, when the moisture content stays nearly constant. In April, the meadow starts to dry. The meadow is driest in July and August. Wetness increases from August to November. The modeled cycle is always similar in shape, but with different magnitudes in wet years, dry years, and climate change years. 


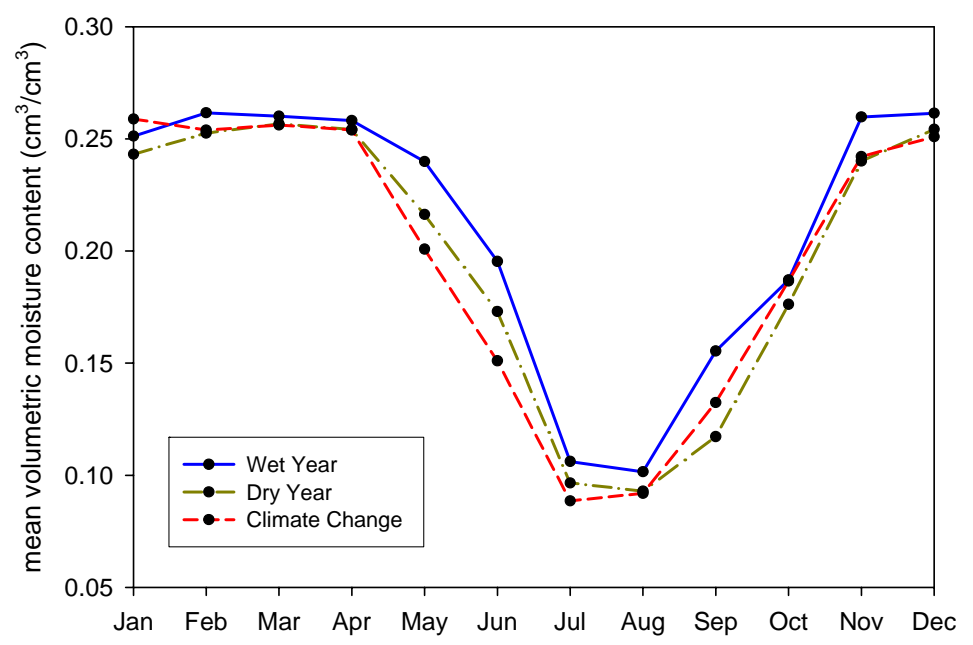

Figure 33. Monthly soil-moisture in wet years, dry years, and climate change years. 


\section{Chapter 4: Discussion}

Seasonal variability in soil-moisture (figure 11) was driven primarily by precipitation and temperature. The meadow was wettest on average in winter because low temperatures and low vegetation growth resulted in minimal evapotranspiration. In spring, precipitation kept the meadow moist as temperatures increased. Although the meadow was wet immediately after large storms in summer, it was driest on average during this season because temperatures and evapotranspiration were high. Mean wetness increased into the fall as temperatures and evapotranspiration decreased.

On a storm time-scale, the mean soil-moisture was highest immediately following storms, and declined steadily after storms because there were no further water inputs (figure 13). Variance was highest mid-dry down, when topography contributes the most to variability. At high moisture contents, variance is controlled by porosity and at low moisture contents variance is controlled by the wilting point. Because soil and vegetation are more spatially uniform at points across the meadow than slopes and aspect, variance is highest under conditions where topography dominates the soil-moisture pattern.

The soil-moisture content in the meadow is directly related to water-table levels in the meadow and, in-turn, to discharge in the surrounding streams. With this knowledge, estimates of soil-moisture can be related to other parts of the water balance. Spatial variability in soil-moisture causes spatial variability in recharge rates, which translates to some parts of the meadow contributing more recharge to ground-water than others.

Observations and modeling results in this study show highest variance at midmoisture levels and the soil-moisture model provides a process-based explanation. Western et al. (2002) wrote that, although it has not been observed in field observations, 
variance at mid-moisture levels is the correct theoretical relationship because of the bounded nature of soil-moisture. The results of this study are different from previous studies because it is in a temperate environment and most previous studies were in wet or semi-arid environments. In wet environments, soil-moisture distributions remain near saturation and rarely reach the wilting point. In semi-arid environments, soil-moisture distributions remain near the wilting point and rarely reach saturation. In temperate environments, soils commonly reach the wilting point and the saturation point; thus, it is possible to observe the pattern of low variance at low moisture contents, high variance at mid-moisture contents, and low variance at high moisture contents. In wet and semi-arid environments, field observations reveal only a fraction of the variance profile.

The model adapted from Teuling and Troch (2005) captured the evolution of soilmoisture patterns in this study reasonably well, and is particularly useful for testing the effects of different variables on soil-moisture patterns under different wetness conditions. The model reproduced the observed trend of maximum variance at mid-moisture contents (figure 25), and showed that variance was controlled by porosity under wet conditions, by the wilting point under dry conditions, and by topography under intermediate conditions. Soil-moisture is directly tied to other parts of the water-balance; when soilmoisture declines, the water-table rises (figure 18). The discharge model reproduced observed low stream flows using the deep drainage component, q, of the soil-moisture model (figure 29), which demonstrates that the soil-moisture model can be applied to study patterns in recharge. The finite-element model (figure 28) illustrates that recharge can be used with a basic knowledge of aquifer properties to simulate ground-water levels and the effects of pumping of ground-water for water supply. The probability plot for 
Lewis Spring shows the chance of monthly flow dropping below a certain level, i.e., there is a $10 \%$ chance of minimum monthly flows dropping below 25 gpm (figure 32); this plot highlights that low-flow statistics can be produced from a soil-moisture dynamics model.

Because the mean soil-moisture in the meadow is related to the spatial pattern (figure 15), the model can be used to infer how changes in precipitation and temperature will affect the size and shape of the wetland. January to April, there is little difference in mean monthly soil-moisture between dry years, wet years, and climate change years (figure 33). April to August, monthly mean soil-moisture in climate change years is lower than in dry years and much lower than in wet years. August to November, monthly mean soil-moisture is lower in dry years than in climate change years and in wet years. Soilmoisture is similar for all years in December. The effect of climate change would be smallest in winter, and largest in the summer.

Seasonal variability in temperature and evapotranspiration can be used to explain the results. The 5C increase from climate change causes increases in evapotranspiration from April to August when plants are most active, and this water loss causes soilmoisture to drop to minimal levels. In August, mean soil-moisture in climate change years is comparable to dry years because the higher temperatures are compensated by the 4\% increase in precipitation. The precipitation increase in climate change years from August to November causes these months to be wetter than the same months in dry years, but still less wet than wet years. If climate change occurs as many predict, soil-moisture levels will decline below the levels that occur as a result of natural climate variability; a change that will impact the soil-moisture patterns and upset the balance of the ecosystem. 
The hydrographs from this study reveal that the aquifers of the shallow wells in the meadow and the deep pumping wells, such as BM-9, are probably not connected. With this knowledge, it is reasonable to infer that ground-water pumping would probably not have a significant influence on the hydrology of the meadow. Variability in soilmoisture levels, water-table levels, and stream discharges in the meadow area is more likely to result from climate change than from ground-water pumping for water supply.

The controls that govern soil-moisture variability at the small catchment scale, and the patterns that exist at different mean moisture contents (figure 15), could be coupled with remote sensing to estimate catchment-scale patterns from satellite images showing soil-moisture averaged over large areas. If fine-scale patterns in catchments can be linked to satellite images, detailed hydrological information about catchments could be extracted from available datasets. This work shows that the mean soil-moisture content in a field is related to distinct soil-moisture patterns, and is tied with other parts of the water balance. The relationship between mean and variance in soil-moisture in a temperate climate zone is explained with a fairly simple model. Further work should aim to simplify the modeling approach to include only the most essential parameters, and to link observed patterns with remote sensing to transfer local knowledge to larger areas. 


\section{References}

Anderson, M. P. and Woessner, W. W. 1992. Applied Groundwater Modeling: Simulation of Flow and Advective Transport. Academic Press, Inc., San Diego, California.

Brocca, L., Morbidelli, R., Melone, F. and Moramarco, T. Soil moisture spatial variability in experimental areas of central Italy. 2007. Journal of Hydrology 333: 356373.

Brubaker, K. L. and Entekhabi, D. Analysis of feedback mechanisms in land-atmosphere interaction. 1996. Water Resources Research 32: 1343-1357.

Carsel, R. F. and Parrish, R. S. Development of joint probability distributions of soil water retention characteristics. 1998. Water Resources Research 24: 755-769.

D'Odorico, P. and Porporato, A. Preferential states in soil moisture and climate dynamics. 2004. Proceedings of the National Academy of Sciences of the United States of America 101: 8848-8851.

D'Odorico, P., Ridolfi, L., Porporato, A. and Rodriguez-Iturbe, I. Preferential states of seasonal soil moisture: The impact of climate fluctuations. 2000. Water Resources Research 36: 2209-2219.

Dekay, R. H. Development of ground-water supplies in Shenandoah National Park, Virginia. 10, 1-158. 1972. Virginia Division of Mineral Resources. Mineral Resources Report.

Dingman, S. L. 2002. Physical hydrology. Prentice Hall, Upper Saddle River, NJ.

Famiglietti, J. S., Devereaux, J. A., Laymon, C. A., Tsegaye, T., Houser, P. R., Jackson, T. J., Graham, S. T., Rodell, M. and van Oevelen, P. J. Ground-based investigation of soil moisture variability within remote sensing footprints during the Southern Great Plains 1997 (SGP97) Hydrology Experiment. 1999a. Water Resources Research 35: 1839-1851.

Famiglietti, J. S., Devereaux, J. A., Laymon, C. A., Tsegaye, T., Houser, P. R., Jackson, T. J., Graham, S. T., Rodell, M. and van Oevelen, P. J. Ground-based investigation of soil moisture variability within remote sensing footprints during the Southern Great Plains 1997 (SGP97) Hydrology Experiment. 1999b. Water Resources Research 35: 1839-1851.

Grayson, R. B., Western, A. W., Chiew, F. H. S. and Bloschl, G. Preferred states in spatial soil moisture patterns: Local and nonlocal controls. 1997. Water Resources Research 33: 2897-2908.

Groisman, P. Ya. and Easterling, D. R. Variability and trends of total precipitation and snowfall over the United States and Canada. 1994. Journal of Climate 7: 184-205. 
Hamon, W. R. Estimating potential evapotranspiration. 1961. Journal of the Hydraulic Division 87: 107-120.

Hornberger, G. M. and Wiberg, P. 2004. Numerical methods in the hydrological sciences. American Geophysical Union,

Kaufmann, R. K. and Stern, D. I. Evidence for human influence on climate from hemispheric temperature relations. 1997. Nature 388: 39-44.

Lee, R. Potential insolation as a topoclimatic characteristic of drainage basins. 1964. International Association of Scientific Hydrology Bulletin 9: 27-41.

Loague, K. Soil water content at R-5,1, Spatial and temporal variability. 1992. Journal of Hydrology 139: 233-251.

Loaiciga, H. A. and et.al. Global warming and the hydrologic cycle. 1996. Journal of Hydrology 174: 83-127.

Lynch, D. D. Hydrologic conditions and trends in Shenandoah National Park, Virginia, 1983-84. USGS Report 87-4131, 1-115. 1987. Richmond, VA.

Martin, L. Drinking water source protection plan, Big Meadows area, Shenandoah National Park. 1-17. 2002. Ft. Collins, CO, NPS-Water Resources Division.

Mills, A. L. 2007. Personal Communication.

Rodriguez-Iturbe, I. Ecohydrology: A hydrologic perspective of climate-soil-vegetation dynamics. 2000. Water Resources Research 36: 3-9.

Teuling, A. J. and Troch, P. A. Improved understanding of soil moisture variability dynamics. 2005b. Geophysical Research Letters 32.

Teuling, A. J., Uijlenhoet, R. and Troch, P. A. On bimodality in warm season soil moisture observations. 2005. Geophysical Research Letters 32.

Western, A. W. and Grayson, R. B. The Tarrawarra data set: Soil moisture patterns, soil characteristics, and hydrological flux measurements. 1998. Water Resources Research 34: 2765-2768.

Western, A. W., Grayson, R. B. and Bloschl, G. Scaling of soil moisture: A hydrologic perspective. 2002. Annual Review of Earth and Planetary Sciences 30: 149-180.

Zhang, R. Determination of soil sorptivity and hydraulic conductivity from the disk infiltrometer. 1997. Soil Sci. Soc. Am. J. 61: 1024-1030. 
Appendix A: Estimation of potential evapotranspiration using the Hamon (1961) method, adapted from (Hornberger and Wiberg 2004).

$$
\begin{aligned}
& e_{s}=0.2749 \times 10^{8} \exp \left[\frac{-4278.6}{T_{t}+242.8}\right] \\
& \mathrm{e}_{\mathrm{s}}=\text { saturated vapor pressure at temperature } \mathrm{T}[\mathrm{kPa}] \\
& \mathrm{T}_{\mathrm{t}}=\text { temperature on day } \mathrm{t}\left[{ }^{\circ} \mathrm{C}\right] \\
& \omega_{\mathrm{s}}=\arccos (-\tan \varphi \tan \delta) \\
& \omega_{\mathrm{s}}=\text { sunset hour of day } \mathrm{t} \\
& \delta=0.4093 \sin \left(\frac{2 \pi}{365} J-1.405\right) \\
& \delta \text { is solar declination } \\
& \mathrm{H}_{\mathrm{t}}=\frac{24 \omega_{s}}{\pi}
\end{aligned}
$$

$$
\begin{aligned}
& \phi \text { is the latitude } \\
& \mathrm{H}_{\mathrm{t}}=\text { average number of daylight hours/day during the month in which day } \mathrm{t} \text { falls }
\end{aligned}
$$

$$
E t=\frac{2.1 H_{t}^{2} e_{s}}{T_{t}+273.3}
$$

$$
\begin{aligned}
& E_{t}=\text { evaporation on day } t[m m \text { day- } 1] \\
& E_{t}=0 \text { on days when } T_{t} \leq 0
\end{aligned}
$$


Appendix B: The equations for calculating slope factor, $\mathrm{S}_{\mathrm{f}}$

$$
\begin{aligned}
\Lambda_{e q}= & \sin ^{-1}[\sin (\beta) \cdot \cos (\alpha) \cdot \cos (\Lambda)+\cos (\beta) \cdot \sin (\Lambda)] \\
& \Lambda_{\text {eq }}=\text { equivalent slope } \\
& \beta=\text { the angle of inclination of the slope } \\
& \alpha=\text { the azimuth }
\end{aligned}
$$

$$
\Delta \Omega=\tan ^{-1}\left[\frac{\sin (\beta) \cdot \sin (\alpha)}{\cos (\beta) \cos (\Lambda)-\sin (\beta) \cos (\alpha)}\right]
$$

$\Delta \Omega=$ difference in longitude between the original slope and the equivalent plane $\Lambda$ = latitude

$\Gamma=\frac{2 \cdot \pi \cdot(J-1)}{365}$

$$
\begin{aligned}
& \Gamma=\text { day angle } \\
& \mathrm{J}=\text { Julian day }
\end{aligned}
$$

$$
\begin{aligned}
& \delta=(180 / \pi) \cdot[0.006918-0.39912 \cdot \cos (\Gamma)+0.070257 \cdot \sin (\Gamma)-0.006758 \cdot \cos (2 \cdot \Gamma) \\
& +0.000907 \cdot \sin (2 \cdot \Gamma)-0.002697 \cdot \cos (3 \cdot \Gamma)+0.00148 \cdot \sin (3 \cdot \Gamma)]
\end{aligned}
$$

$\delta=$ declination of the sun

$T_{s r}=-\frac{\cos ^{-1}\left[-\tan \left(\Lambda_{e q}\right) \cdot \tan (\delta)\right]-\Delta \Omega}{\omega}$

$$
\mathrm{T}_{\mathrm{sr}}=\text { time of sunrise }
$$

$\omega=$ angular velocity of the earth's rotation, $15^{\circ} / \mathrm{hr}$

$$
T_{s s}=+\frac{\cos ^{-1}\left[-\tan \left(\Lambda_{e q}\right) \cdot \tan (\delta)\right]-\Delta \Omega}{\omega}
$$

$$
\mathrm{T}_{\mathrm{ss}}=\text { time of sunset }
$$

$$
\begin{aligned}
& E_{0}=1.000110+0.034221 \cdot \cos (\Gamma)+0.001280 \cdot \sin (\Gamma) \\
& +0.000719 \cdot \cos (2 \cdot \Gamma)+0.000077 \cdot \sin (2 \cdot \Gamma)
\end{aligned}
$$

$$
\mathrm{E}_{0}=\text { eccentricity correction }
$$




$$
\begin{aligned}
& K_{E T}=I_{s c} \cdot E_{0} \cdot\left\{\cos \left(\Lambda_{e q}\right) \cdot \cos (\delta) \cdot \frac{\left[\sin \left(\omega \cdot T_{s s}+\Delta \Omega\right)\right]}{\omega}+\sin \left(\Lambda_{e q}\right) \cdot \sin (\delta) \cdot\left(T_{s s}-T_{s r}\right)\right\} \quad \text { B.7 } \\
& \mathrm{I}_{\mathrm{sc}}=\text { solar constant, } 1367 \mathrm{~W} \mathrm{~m}^{-2} \\
& K_{d i r}^{\prime}=\tau \cdot K_{E T}^{\prime} \\
& \mathrm{K}_{\text {dir }}^{\prime}=\text { direct solar radiation } \\
& \tau=\text { total atmospheric transmissivity } \\
& K_{\text {dif }}^{\prime}=0.5 \cdot \gamma_{s} \cdot K_{E T}^{\prime} \\
& \mathrm{K}_{\mathrm{dif}}=\text { diffuse radiation } \\
& \gamma_{\mathrm{s}}=\text { attenuation of the solar beam due to scattering } \\
& K_{g}^{\prime}=K_{d i r}^{\prime}+K_{d i f}^{\prime} \\
& \mathrm{K}_{\mathrm{g}}^{\prime}=\text { global radiation } \\
& K_{b s}^{\prime}=0.5 \cdot \gamma_{s} \cdot a \cdot K_{g}^{\prime} \\
& \mathrm{K}_{\mathrm{bs}}^{\prime}=\text { backscattered radiation } \\
& \mathrm{a}=\text { albedo } \\
& K_{c s}=\tau \cdot K_{E T}+K_{d i f}^{\prime}+K_{b s}^{\prime} \\
& \mathrm{K}_{\mathrm{cs}}^{\prime}=\text { total clear sky radiation incident on a sloping plane } \\
& K_{c s}^{\prime}=\left(\tau+0.5 \cdot \gamma_{s} \cdot a \cdot \tau+0.5 \cdot \gamma_{s}+0.25 \cdot \gamma_{s}^{2} \cdot a\right) \cdot K_{E T}^{\prime} \\
& \mathrm{K}_{\mathrm{cs}}^{\prime}=\text { total clear sky radiation incident on a horizontal plane at the surface } \\
& S_{f}=\frac{K_{c s}}{K_{c s}^{\prime}} \\
& \mathrm{S}_{\mathrm{f}}=\text { slope factor }
\end{aligned}
$$

